\title{
Guidelines for the Evaluation and Treatment of Perimenopausal Depression: Summary and Recommendations
}

\author{
Pauline M. Maki, PhD, ${ }^{1, *}$ Susan G. Kornstein, MD, ${ }^{2, *}$ Hadine Joffe, MD, MSc, \\ Joyce T. Bromberger, $\mathrm{PhD}^{4}$, Ellen W. Freeman, $\mathrm{PhD}^{5}$, Geena Athappilly, MD, \\ William V. Bobo, MD, MPH, Leah H. Rubin, $\mathrm{PhD}^{8}$, Hristina K. Koleva, MD, \\ Lee S. Cohen, MD, ${ }^{10}$ Claudio N. Soares, MD, PhD, MBA, ${ }^{11}$ \\ on behalf of the Board of Trustees for The North American Menopause Society (NAMS) \\ and the Women and Mood Disorders Task Force of the National Network of Depression Centers
}

\begin{abstract}
There is a new appreciation of the perimenopause-defined as the early and late menopause transition stages as well as the early postmenopause-as a window of vulnerability for the development of both depressive symptoms and major depressive episodes. However, clinical recommendations on how to identify, characterize and treat clinical depression are lacking. To address this gap, an expert panel was convened to systematically review the published literature and develop guidelines on the evaluation and management of perimenopausal depression. The areas addressed included: (1) epidemiology; (2) clinical presentation; (3) therapeutic effects of antidepressants; (4) effects of hormone therapy; and (5) efficacy of other therapies (e.g., psychotherapy, exercise, and natural health products). Overall, evidence generally suggests that most midlife women who experience a major depressive episode during the perimenopause have experienced a prior episode of depression. Midlife depression presents with classic depressive symptoms commonly in combination with menopause symptoms (i.e., vasomotor symptoms, sleep disturbance), and psychosocial challenges. Menopause symptoms complicate, co-occur, and overlap with the presentation of depression. Diagnosis involves identification of menopausal stage, assessment of co-occurring psychiatric and menopause symptoms, appreciation of the psychosocial factors common in midlife, differential diagnoses, and the use of validated screening instruments. Proven therapeutic options for depression (i.e., antidepressants, psychotherapy) are the front-line treatments for perimenopausal depression. Although estrogen therapy is not approved to treat perimenopausal depression, there is evidence that it has antidepressant effects in perimenopausal women, particularly those with concomitant vasomotor symptoms. Data on estrogen plus progestin are sparse and inconclusive.
\end{abstract}

Keywords: antidepressants, depression, depressive symptoms, estrogen, menopause, perimenopause, psychotherapy

\footnotetext{
${ }^{1}$ Department of Psychiatry and Department of Psychology, University of Illinois at Chicago, Chicago Illinois.

${ }^{2}$ Department of Psychiatry and Institute of Women's Health, Virginia Commonwealth University, Richmond, Virginia.

${ }^{3}$ Connors Center for Women's Health and Department of Psychiatry, Brigham and Women's Hospital and Dana Farber Cancer Institute/ Harvard Medical School, Boston, Massachusetts.

${ }^{4}$ Department of Epidemiology, Department of Psychiatry, University of Pittsburgh, Pittsburgh, Pennsylvania.

${ }^{5}$ Department of Obstetrics and Gynecology and Department of Psychiatry, University of Pennsylvania, Philadelphia, Pennsylvania.

${ }^{6}$ Edith Nourse Rogers Memorial Veterans Hospital, Bedford Massachusetts; Harvard Medical School, Boston Massachusetts.

${ }^{7}$ Department of Psychiatry and Psychology, Mayo Clinic, Rochester, Minnesota.

${ }^{8}$ Department of Neurology, Johns Hopkins University School of Medicine, Baltimore, Maryland.

${ }^{9}$ University of Iowa Carver College of Medicine, Iowa City, Iowa.

${ }^{10}$ Department of Psychiatry, Massachusetts General Hospital and Harvard Medical School, Boston, Massachusetts.

${ }^{11}$ Department of Psychiatry, Queen's University School of Medicine, Ontario Canada.

*Pauline M. Maki and Susan G. Kornstein are co-first authors.

This article is being co-published in Journal of Women's Health and Menopause: The Journal of the North American Menopause Society.
} 


\section{Introduction}

$\mathbf{T}$ HE EXISTENCE OF HORMONE-RELATED MOOD SYMPTOMS or "windows of vulnerability" for reproductive-related depression across the female lifecycle has gained attention in recent decades. ${ }^{1,2}$ Epidemiologic findings, animal data and clinical observations have shed some light into plausible mechanistic hypotheses on why some but not all women may be particularly sensitive to changes in the hormonal milieu experienced premenstrually, during the postpartum period or during the menopause transition. ${ }^{3-9}$ The notion of a menopauseassociated depression, however, has been the focus of clinical and scientific debate for years. The lack of consensus on this issue has also led to a lack of clarity in how to evaluate and treat depression in women during the menopausal transition and postmenopausal period.

To address this gap and to provide guidelines for health care practitioners, The North American Menopause Society (NAMS) and the National Network of Depression Centers Women and Mood Disorders Task Group (NNDC) collaborated to convene an 11-member expert panel to systematically review the scientific literature on depressive disorders and depressive symptoms in perimenopausal and postmenopausal women and develop clinical guidelines. The panel addressed five topics pertaining to depressive symptoms and depressive disorders during the perimenopause, including: (1) epidemiology; (2) clinical presentation; (3) therapeutic effects of antidepressants; (4) effects of hormone therapy (HT); and (5) efficacy of other therapies (e.g., psychotherapy, exercise, and natural health products). This review did not focus on the mood benefits of HT and non-hormonal treatments for vasomotor symptoms (VMS), as these are covered in NAMS position statements. ${ }^{10,11}$ General guidelines for the treatment of Major Depressive Disorder (MDD) are available; ${ }^{12}$ therefore, those issues are not covered here. Instead, these guidelines focus on issues relating specifically to depressive symptoms and depressive disorders in midlife women.

\section{Methodology}

Panel members reviewed the published literature related to perimenopausal and postmenopausal women in the following areas: epidemiology of depressive symptoms and depressive disorders (J.B., L.R.); the clinical presentation of depression (H.J., G.A.); the therapeutic effects of antidepressant medication on clinical depression (L.C., H.K.); the effects of hormone therapy on depression (C.S.); and the effect of other therapies on depression (W.B., E.F.). Each subgroup of experts reviewed the published literature (Medline/PubMed/PsychInfo/EMbase) for relevant clinical studies using select search terms (see each section below), then they wrote a summary of their literature review and drafted a set of clinical recommendations. These were shared with each panel member via email for feedback and each subgroup was assigned to carefully review one other topic area. The panel co-chairs (PM, SK) drafted a set of guidelines based on the literature reviews. Panel members vetted the guidelines and voted on a final set of recommendations. The preliminary guidelines were presented at the 2016 NAMS Annual Meeting and the 2017 World Congress on Women's Mental Health, and feedback from those presentations was incorporated into final vetting of the guidelines, including the addition of a section on Specific Populations to address issues related to depression, hysterectomy with or without oophorectomy and primary ovarian insufficiency.

The literature (English only) in each section was reviewed in a systematic manner for publications between 1980 and 2015. Each section included a search with the following terms containing the MeSH terms "depression," "depressed," "depressive," "anxiety," or "mood" in combination with the terms "perimenopause," "menopausal transition," "menopause," "menopausal," "postmenopausal," "premenopause," or "midlife" as well as additional terms and inclusion/exclusion criteria specific to that section. Additional search terms were used for each topic area including epidemiology ("epidemiology," "prevalence," or "risk"), clinical presentation ("symptoms," "presentation," “diagnosis," "screening," "scales,"), antidepressants ("antidepressant," "SSRI," “SNRI”), hormone therapy (estrogen therapy", "hormone therapy", "hormone replacement therapy", "estrogen," "oestrogen," and "'estradiol.") and other therapies ("psychotherapy", "'electroconvulsive therapy," "neuromodulation," "transcranial magnetic stimulation," "vagus nerve stimulation," “deep brain stimulation," "luminotherapy," "bright light therapy," "sleep deprivation," "wake therapy," "acupuncture," "exercise," "Hypericum perforatum," "St. John's wort," "Cimifuga racemosa," "Black cohosh," "S-adenosyl-Lmethionine," “SAMe," “phytoestrogens," “ginseng," "ginkgo biloba," "folate," "l-methylfolate," and "omega 3 fatty acids"). Each of the three intervention sections included only those clinical trials that selectively enrolled women with clinical depression and excluded studies that examined mood benefits in non-depressed women.

The epidemiology section addressed the following three questions with systematic reviews: (1) In cross-sectional studies, what is the relationship between perimenopause stage and depressive symptoms? (2) In longitudinal studies, what is the relationship between perimenopause stage and depressive symptoms? (3) In longitudinal studies, what are the risk factors for depressive symptoms/disorder in perimenopause? Four inclusion criteria were applied: (1) community-dwelling samples, not clinical settings, (2) sample size $\geq 200$, with 50 or more in each menopause stage, (3) a standard depression inventory with a validated cutoff score to indicate "depressive symptoms" or the use of a structured clinical interview to indicate "diagnosed depressive disorder," and (4) specification and application of standard criteria to determine menopause status (e.g., Stages of Reproductive Aging Workshop Plus 10 $[\text { STRAW }+10]^{13}$ or Study of Women's Health Across the Nation $[\mathrm{SWAN}]^{14}$ criteria; specific criteria for irregularity, number of missed periods, last bleed). We use the definition of perimenopause from the STRAW +10 criteria, where perimenopause is defined as the early and late menopause transition stages as well as the early postmenopause. ${ }^{13}$ Note that this definition differs from SWAN where perimenopause includes early and late perimenopause but not the postmenopause. Also, given that the SWAN provides the longest follow-up period13 years of follow-up for a sample of women aged 42-52 years at baseline - it is important to recognize that this body of work includes women with a maximum age of 65 and is not meant to address the topic of geriatric depression. Additionally, the following two sections were added following feedback from NAMS: (4) "Is hysterectomy with and without oophorectomy a risk factor for depressive symptoms/disorders?" and (5) "Is Premature Ovarian Insufficiency (POI) linked to depression?" 
The section on the presentation of depression addressed: (1) Is there a unique or characteristic clinical presentation of depressive disorders during the menopause transition? (2) How is depression diagnosed during the menopause transition? What is the differential diagnosis of depression during the menopausal transition? (3) What symptoms commonly co-occur with depression in midlife women? (4) What are the unique psychosocial challenges associated with the menopause transition that might contribute to depressive symptoms? and (5) What screening measures have been validated for assessing depression and depressive symptoms? Studies that were published in a peer-reviewed journal, published in the English language, and utilized a validated or standard screening scale to assess one or one or more of the following: (i) menopausal symptoms, (ii) psychological distress, (iii) depressive disorders, (iv) depressive symptoms, (v) mood symptoms, and (vi) quality of life during menopause, were included.

The section on antidepressants addressed four questions: (1) What are the therapeutic effects of antidepressants on major depressive episodes (MDE) in perimenopausal and postmenopausal women? (2) Are there differences in efficacy between types of antidepressants in the treatment of peri- or postmenopausal women with MDD? (3) Does clinical response to antidepressants differ according to menopause status? (4) Does estrogen therapy improve antidepressant response in peri-or postmenopausal women with MDD? Only studies meeting the following criterion were included: (a) use of validated instruments to measure depression (e.g., Hamilton Depression Rating Scale [HDRS], MontgomeryÅsberg Depression Rating Scale [MADRS], Beck Depression Inventory [BDI], Patient Health Questionnaire-9 [PHQ-9]).
The section on hormone therapy addressed the following questions: (1) Does HT have an effect on depressive disorders in perimenopausal women? (2) Does HT have an effect on depressive disorders in postmenopausal women? and (3) Does HT prevent depressive symptoms during the menopausal transition? The section was guided by a recent, comprehensive systematic review on the efficacy of estrogen-based interventions. ${ }^{15}$ The following inclusion criteria were applied: (1) clinical administration of estrogen-based HT, and (2) assessment of mood symptoms/depression with standardized instruments. Nonintervention studies and studies using nonestrogen-based preparations or hormone-analogue agents (selective estrogen-receptor modulators [SERMs]) were excluded from further consideration. Additionally, following feedback from NAMS, a section on hormonal contraceptives for perimenopausal women was added.

The section on other therapies on depression addressed efficacy of treatment modalities in classes that include: (1) psychotherapies, (2) somatic/physical therapies (neuromodulatory treatments, light therapy, exercise), and (3) natural products (i.e., nutraceutical therapies and botanical/herbal therapies).

\section{Epidemiology of Depressive Symptoms and Depressive Disorders in Midlife Women}

In cross-sectional studies, what is the relationship between perimenopause stage and depressive symptoms?

Numerous cross-sectional studies have addressed whether perimenopausal women demonstrate a higher prevalence of or are at risk for depressive symptoms compared with premenopausal women (Table 1). Sample sizes in these crosssectional studies ranged from 376 to 6383 women (median,

Table 1. Cross-Sectional Studies of Prevalence or Odds of Depressive Symptoms in Perimenopause Compared to Premenopause

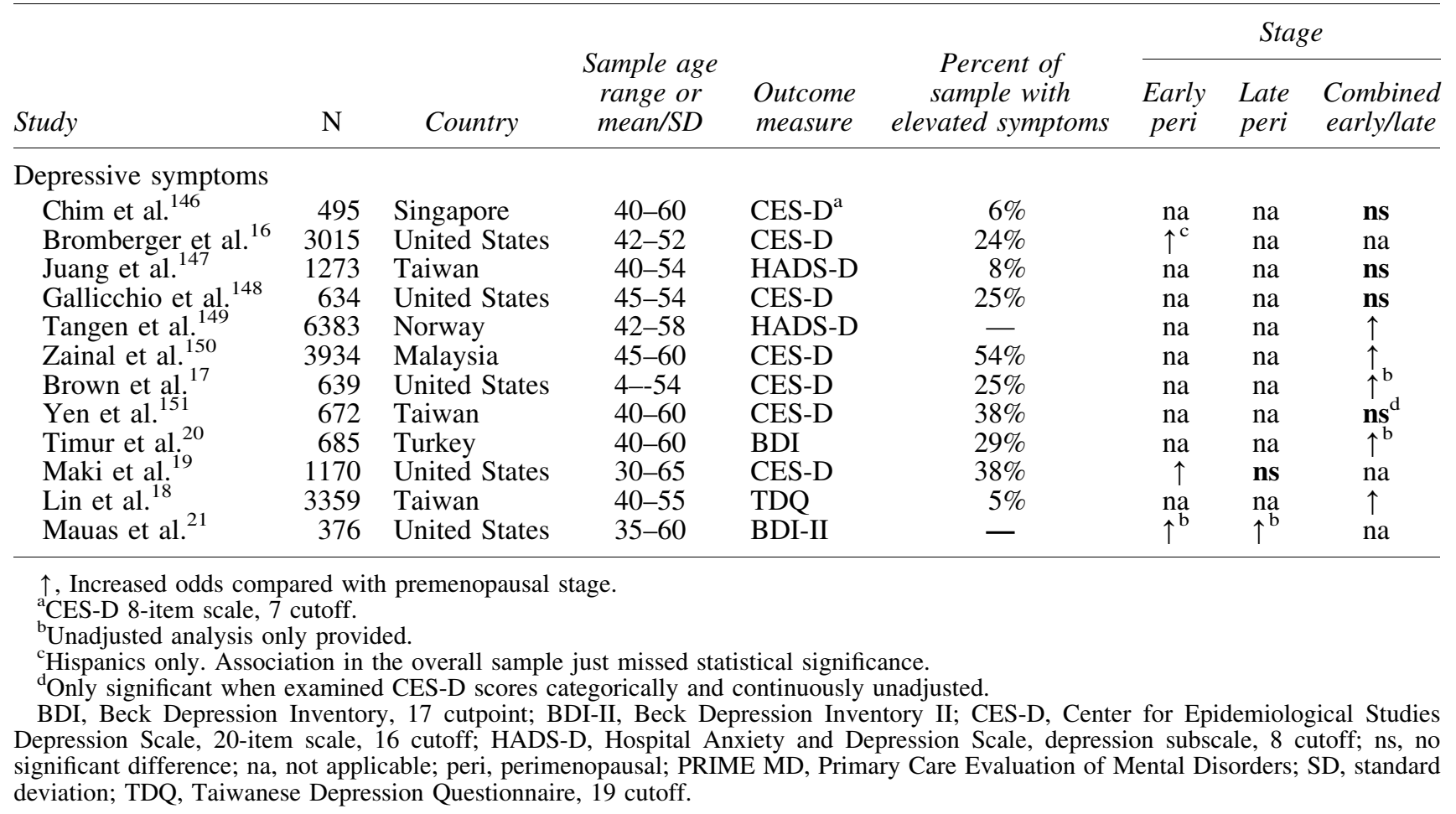


927), and most samples included women aged between 40 and 60 years, representing six different countries, a range of ethnicities, and a range of educational attainment.

Although all studies had an adequate sample size to provide an acceptable prevalence estimate of elevated depressive symptoms in the overall sample, comparisons of elevated depressive symptoms in perimenopausal versus premenopausal women may have been underpowered in samples with a low prevalence of elevated depressive symptoms and relatively small sample sizes. The analytic approach varied, with some studies reporting adjusted results and others unadjusted. Eight of the 12 studies included found that elevated depressive symptoms were significantly more prevalent in perimenopausal versus premenopausal women, and six of these were adjusted for covariates. ${ }^{16-20}$ These studies suggest that $45 \%$ to $68 \%$ of perimenopausal women report elevated depressive symptoms compared with $28 \%$ to $31 \%$ of premenopausal women. ${ }^{17,20}$ In early perimenopause, $28 \%$ to $47 \%$ of women reported elevated depressive symptoms ${ }^{16,19}$ and the odds of elevated depressive symptoms in this stage was higher than in the premenopausal stage. In a large cohort of ethnically diverse women, early perimenopausal women showed a 1.74-fold increased odds of elevated depressive symptoms during early perimenopause ${ }^{19}$ and among Hispanic women there was a 2.45 -fold increased odds. ${ }^{16}$ It is difficult to conclude whether women in the late-perimenopause stage demonstrate elevated depressive symptoms because of the two cross-sectional studies that specifically included this group of women, one included only 57 women in this stage ${ }^{19}$ and the other only examined depressive symptoms continuously. ${ }^{21}$

\section{In longitudinal studies, what is the relationship between perimenopause stage and depressive symptoms?}

Prospective longitudinal studies from three U.S. cohorts addressed whether the perimenopausal stage is a period of increased risk for both depressive symptoms and depressive disorders as measured by diagnostic clinical interviews (See Table 2). These cohorts include SWAN, ${ }^{14,22-24}$ the Penn Ovarian Aging Study (POAS), ${ }^{25-28}$ and the Seattle Midlife Women's Health Study. ${ }^{29}$ Compared with cross-sectional studies, longitudinal studies are more optimally designed to address the association between menopause transition stage and depression as well as the direction of the association. Sample sizes in longitudinal studies sizes ranged from 151 to 3,302 (median, 332), and median length of follow-up was 7 years (range, 3-15 years). Women across studies were ethnically diverse and primarily well educated. Of the 11 longitudinal studies reviewed, six (54\%) suggest an increased risk of depressive symptoms during the transition, ${ }^{14,24,26,27,29,30}$ with estimates of a 1.30 to 1.55 increased likelihood of depressive symptoms in the early transition and 1.71 to 2.89 increase in the late transition. ${ }^{14,24,27}$ Two studies indicate that in women with no previous history of depression, ${ }^{26,27,30}$ the transition poses a greater risk for elevated

Table 2. Longitudinal Studies of Odds of Depressive Symptoms/Disorder During the Perimenopause Compared to Premenopause

\begin{tabular}{|c|c|c|c|c|c|c|c|c|}
\hline \multirow[b]{2}{*}{ Study } & \multirow[b]{2}{*}{$\mathrm{N}$} & \multirow{2}{*}{$\begin{array}{l}\text { Length of } \\
\text { follow-up } \\
\text { (years) }\end{array}$} & \multirow[b]{2}{*}{ Country } & \multirow{2}{*}{$\begin{array}{c}\text { Age range or } \\
\text { mean/SD at } \\
\text { study entry }\end{array}$} & \multirow[b]{2}{*}{$\begin{array}{l}\text { Outcome } \\
\text { measure }\end{array}$} & \multicolumn{3}{|c|}{ Stage } \\
\hline & & & & & & $\begin{array}{c}\text { Early } \\
\text { peri }\end{array}$ & $\begin{array}{l}\text { Late } \\
\text { peri }\end{array}$ & $\begin{array}{l}\text { Combined } \\
\text { early/late }\end{array}$ \\
\hline \multicolumn{9}{|l|}{ Depressive symptoms } \\
\hline Avis et al. ${ }^{152}$ & 2565 & 5 & United States & $45-55$ & CES-D & na & na & ns \\
\hline Maartens et al. ${ }^{153}$ & 2103 & 3.5 & Netherlands & 51.8 & EDS & na & na & ns \\
\hline Freeman et al. ${ }^{27}$ & $\begin{array}{l}332 \\
152^{\mathrm{a}}\end{array}$ & 4 & United States & $35-47$ & CES-D & $\uparrow$ & $\begin{array}{l}\uparrow \\
\text { ns }\end{array}$ & na \\
\hline Freeman et al. ${ }^{26}$ & $231^{\mathrm{a}}$ & 8 & United States & $35-47$ & CES-D & na & na & $\uparrow$ \\
\hline Cohen et al. ${ }^{30}$ & $460^{\mathrm{a}}$ & 3 & United States & $36-45$ & CES-D & na & na & $\uparrow$ \\
\hline Bromberger et al. ${ }^{14}$ & 3302 & 7 & United States & $42-52$ & CES-D & $\uparrow$ & $\uparrow$ & na \\
\hline Woods et al. ${ }^{29}$ & 302 & 15 & United States & $33-55$ & CES-D & ns & $\uparrow$ & na \\
\hline Bromberger et al. ${ }^{24}$ & 3296 & 8 & United States & $42-52$ & CES-D & $\uparrow$ & $\uparrow$ & na \\
\hline Morrison et al. 28 & 436 & 11 & United States & $35-47$ & CES-D & $\downarrow$ & $\downarrow$ & na \\
\hline Freeman et al. ${ }^{25}$ & $203^{b}$ & 14 & United States & $42.8 \pm 3.1$ & CES-D & na & na & $\begin{array}{l}\uparrow \text { Compared } \\
\text { to FMP }\end{array}$ \\
\hline \multicolumn{9}{|l|}{ Depression Diagnosis } \\
\hline Freeman et al. ${ }^{27}$ & 332 & 4 & United States & $35-47$ & PRIME MD & ns & ns & na \\
\hline Freeman et al. ${ }^{26}$ & $231^{\mathrm{a}}$ & 8 & United States & $35-47$ & PRIME MD & na & na & ns \\
\hline Bromberger et al. ${ }^{32}$ & $266^{\mathrm{a}}$ & & & & & ns & ns & ns \\
\hline Bromberger et al. ${ }^{22}$ & 221 & 10 & United States & $42-52$ & SCID & na & na & $\uparrow$ \\
\hline Morrison et al. ${ }^{28}$ & 436 & 11 & United States & $35-47$ & PRIME MD & ns & $\downarrow$ & na \\
\hline \multirow[t]{2}{*}{ Bromberger et al. ${ }^{23}$} & $274^{\mathrm{a}}$ & 13 & United States & $42-52$ & SCID & na & na & ns \\
\hline & $151^{\mathrm{c}}$ & & & & & na & na & $\uparrow$ \\
\hline
\end{tabular}

$\uparrow$, Increased odds compared with premenopausal stage; $\downarrow$, decreased odds compared with premenopausal stage.

${ }^{\mathrm{a} W}$ Women with no history of clinical depression at baseline.

${ }^{\mathrm{b}}$ Compared the effect of menopausal status in a different way, using final menstrual period as the point of comparison.

${ }^{\mathrm{c}}$ Women with a history of clinical depression at baseline; no notations indicates samples that include women with and without clinical depression.

EDS, Edinburgh Depression Scale, 12 cutoff; SCID, Structured Clinical Interview for the Diagnosis of DSM-IV Axis I Disorders. 
depressive symptoms than does remaining premenopausal, especially in those with a history of adverse life events ${ }^{30}$ or vasomotor symptoms (VMS) during perimenopause. ${ }^{30} \mathrm{Al}-$ though the majority of studies focused on the menopausal transition, the POAS examined risk in relation to the final menstrual period (FMP). When a sizeable number of women reached postmenopause in the POAS, the risk of elevated depressive symptoms was significantly higher before the FMP with a lower risk after the FMP. ${ }^{25}$ Whether women with greater racial and economic diversity show the same risk of MDD is unclear, as selection bias can affect estimates of new onset depression, particularly in studies selecting for women with no history of MDD. ${ }^{31}$

Two longitudinal studies evaluated the risk of a MDE during the menopause transition using the Primary Care Evaluation of Mental Disorders (POAS) ${ }^{27}$ or the Structured Clinical Interview for Depression (SWAN) ${ }^{22}$ In adjusted analyses, the SWAN reported that women were two to four times more likely to experience a major depressive episode during the menopause transition and early postmenopause, whereas no increased risk was found during these periods in the POAS. ${ }^{26,27}$ In the POAS, few women transitioned through late perimenopause and postmenopause, so there is greater confidence in findings related to the early perimenopause than later in the transition. ${ }^{26,27}$ In SWAN, the women at greatest risk for MDE during the menopause transition and after were those with a history of MDD before midlife. ${ }^{23,32}$ Indeed, the largest studies have not found that the risk of a MDD episode during the transition is increased when there is no prior history of MDD. ${ }^{23}$ A longitudinal SWAN study compared risk factors for an MDD episode in 151 women with a history of MDD compared to 274 women without a history of MDD. ${ }^{23}$ Women with a history of MDD had a higher risk of developing MDD during midlife compared with women without a history of MDD (59\% vs. $28 \%$ ). ${ }^{23}$ Additionally the risk for MDD was higher in the peri- versus premenopausal stage only for women with a history of MDD. ${ }^{23}$ Overall the elevated risk for MDD in the perimenopause compared to the premenopause was primarily seen among women with a history of MDD, with inconsistent evidence of an increased risk in women without MDD prior to midlife.

\section{In longitudinal studies, what are the risk factors for depressive symptoms/disorders during the perimenopause?}

Longitudinal studies from the United States, the Netherlands, and Australia revealed a wide range of risk factor domains for depressive symptoms and disorders (Table 3). These include demographic characteristics (financial problems; unemployment; being black, Hispanic, or Japanese; $<50$ years old; low education); somatic symptoms (VMS, bothersome symptoms, sleep problems); health related issues (prior depression, poor self-rated health, prior premenstrual complaints, severe premenstrual syndrome, use of psychotropic medications, high body mass index, history of postpartum blues, nulliparity, current antidepressant use, smoking, history of anxiety, chronic medical condition, low role functioning due to physical problems); psychosocial factors (death of partner, major stressful life event, negative attitudes toward aging and menopause, daily hassles, low social support, high trait anxiety, few close friends, tendency to ruminate); and hormones (mean and variability in folliclestimulating hormone [FSH] and estradiol, and mean inhibin). As shown in Table 3, the evidence of an association between VMS and depressed mood is inconsistent. In SWAN there is a strong association between VMS and elevated depressive symptoms ${ }^{14}$ but only a borderline significant association $(p<0.10)$ between frequent VMS and an MDD episode. ${ }^{21}$ The POAS found the opposite pattern of results, with a significant association between VMS and MDE but not depressive symptoms. ${ }^{27}$ Inconsistencies may be due to different definitions of VMS (e.g., any, $\geq 6$ days/2 weeks) and to the way MDD was assessed. For VMS, the association is primarily with depressive symptoms, rather than MDD. Overall, multiple and varying exposures including socioeconomic, individual psychological and social characteristics, and health factors are associated with increased risk for depressive symptoms and MDD during the menopause transition.

\section{Is hysterectomy with and without oophorectomy a risk factor for depressive symptoms/disorders?}

Studies examining the association between depression and hysterectomy with or without oophorectomy have yielded mixed results. ${ }^{3-37}$ In an early randomized trial of ET or ET plus androgen therapy in premenopausal women, depressive symptoms worsened immediately following hysterectomy with oophorectomy, and improved significantly more with ET or ET plus androgen therapy than placebo. ${ }^{38} \mathrm{~A}$ recent meta-analysis of studies published before 2012 identified 22 studies acceptable for inclusion (maximum sample size $=$ 1162 women; maximum follow-up $=12$ years) and concluded that symptoms of depression were significantly reduced following hysterectomy. ${ }^{33}$ However, the quantitative analyses combined postmenopausal women and women with oophorectomy, precluding consideration of the effects of estrogen withdrawal on depression in premenopausal women. Longitudinal studies since that time have revealed an elevated risk of depression following hysterectomy with and without ovarian conservation. ${ }^{34,35}$ For example, a study of 5336 women from the Australian Longitudinal Study on Women's Health found that the risk of elevated depressive symptoms was $20 \%$ higher in women with a hysterectomy and ovarian conservation and $44 \%$ higher in women with a hysterectomy without ovarian conservation compared to women without a hysterectomy. ${ }^{35}$ Women on ET in that study reported higher levels of depressive symptoms than women not on ET. However, because this was not a randomized trial of ET, this association might not reflect a causal effect of ET on depression but instead might indicate that HT was prescribed to treat depressive symptoms, although their depressive symptoms persisted. A population-based study of 8,441 Taiwanese women followed for up to 10 years revealed that compared to women without a hysterectomy, those with a hysterectomy had a $78 \%$ higher risk of elevated depressive symptoms and an $84 \%$ risk of MDD. ${ }^{34}$

\section{Is Premature Ovarian Insufficiency linked to depression?}

Premature ovarian insufficiency or primary ovarian insufficiency (POI) is a clinical syndrome defined by loss of ovarian activity before the age of 40 and affects $1 \%$ of women. ${ }^{39}$ There are few studies examining the prevalence of depression in women with POI. The lifetime prevalence of 


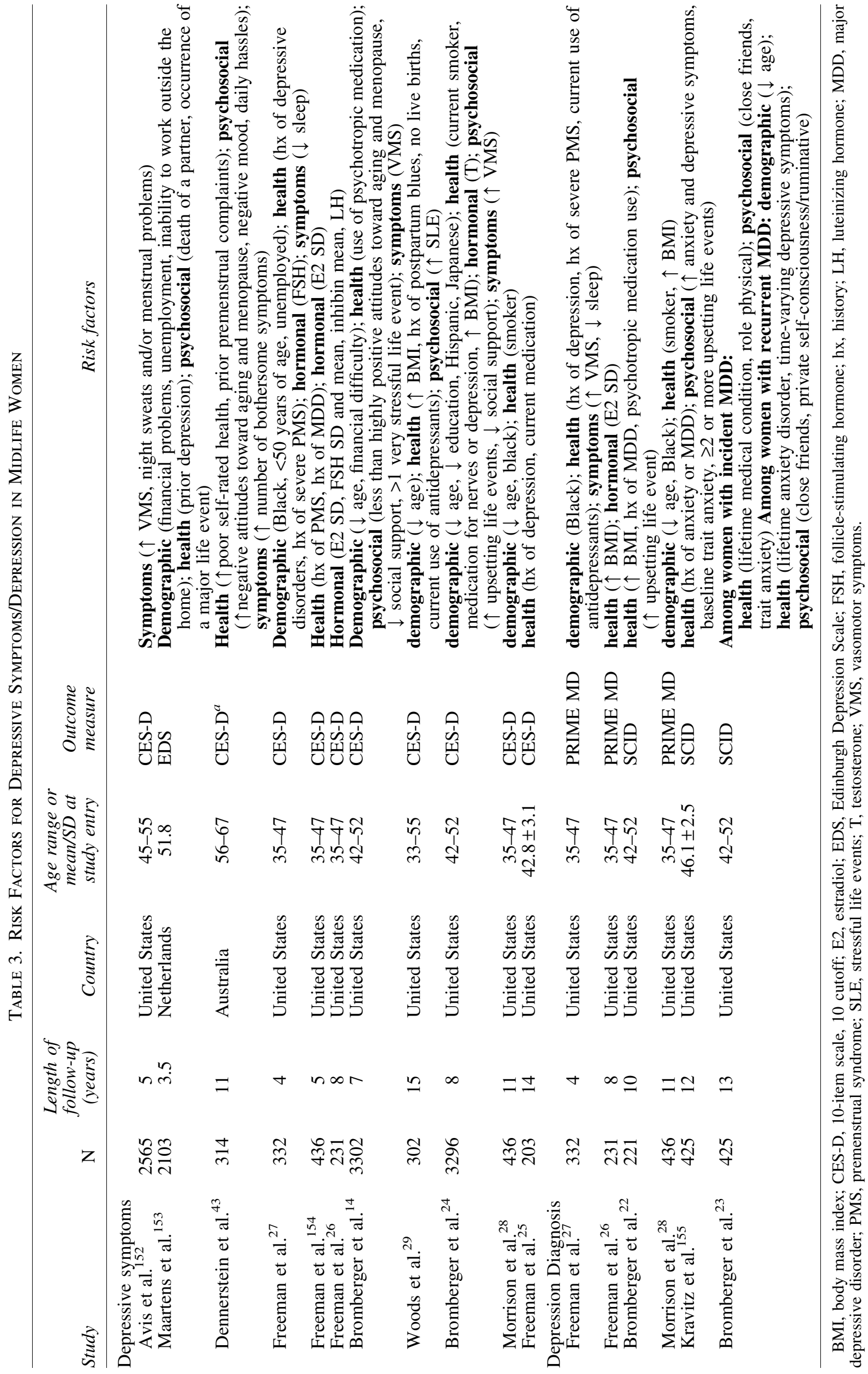


depression was found to be significantly higher in women with spontaneous $46, \mathrm{XX}$ POI $(54.5 \%)$ compared with the general population (20\%) and occurred as commonly before as after the onset of menstrual irregularity-a proxy for the early stages of ovarian insufficiency. ${ }^{40}$ In addition to menopause symptoms, concerns about fertility and long-term health consequences are associated with reduced psychological wellbeing in women with POI. ${ }^{41,42}$

\section{Clinical Presentation of Depression}

\section{Is there a unique or characteristic clinical presentation of depressive disorders during the menopause transition?}

Depression during midlife, presents with classic depressive symptoms, commonly in combination with menopausespecific symptoms and psychosocial challenges. The menopause transition and early postmenopausal stage are reproductive stages associated with increased risk for $\mathrm{MDE}^{22}$ and are also transient windows of vulnerability for the development of subthreshold depressive symptoms. ${ }^{26,27,29,30,43,44}$ The menopause transition generally spans 4 to 8 years; however, the onset of the menopause transition, compared with other reproductive transitions, is less distinct and reflects underlying hormone changes that precede the clinical markers by a variable period of time. ${ }^{45}$ Difficulties in establishing the temporal association of the onset of mood changes with the menstrual markers of the menopause transition may partly explain the relative paucity of data describing unique presentations of clinical depression during and after the menopause transition. ${ }^{46}$ In addition, although major strides have been made to ensure standardization, historically there has been a lack of consistency in defining depression during the menopause transition, distinguishing the severities of depression at this stage and using uniform rating tools. ${ }^{47}$

\section{How is depression diagnosed during the menopause transition?}

Comprehensive diagnosis of depressive disorders during midlife may involve an identification of the stage of menopause as well as clinical assessment of depressive symptoms and other psychiatric conditions. The differential diagnosis of depression during the menopause transition and after surgical menopause includes MDD, subsyndromal depression, adjustment disorder, psychological distress, bereavement, bipolar depression, and general medical causes of depression. Most women who experience a MDE during the menopause transition have had a history of MDD; therefore, the episode represents recurrence of their illness. ${ }^{23}$ First lifetime onset of MDD during the menopause transition is less common. ${ }^{23}$

During the menopause transition and postmenopause, a woman may experience more losses compared with previous stages of her life. Similarly, she may also experience life stressors unique to her midlife stage (e.g., caring for aging parents, sometimes while caring for children; career shifts); hence, bereavement and adjustment disorder are important to consider in the differential diagnosis.

Some women also may experience psychological distress related to awareness of aging, body changes associated with reproductive aging, and concurrent health conditions. ${ }^{48}$ Although surgical menopause may present concerns about fertility and premature aging, data surrounding surgical menopause's association with increased or decreased risk of psychological distress are largely mixed. ${ }^{49}$ Psychological distress is to be differentiated from subsyndromal or minor depression. ${ }^{50}$ Minor depression is characterized by exhibiting two to four symptoms of a MDE, including dysphoria or anhedonia, with associated distress and/or functional impairment.

Mood swings are also common during the menopause transition. ${ }^{51}$ Previous psychiatric history, collateral, and careful delineation of symptoms may assist in differentiating mood swings commonly experienced during the menopause transition from a diagnosis of bipolar disorder. Prospective studies have demonstrated an increased likelihood of mood exacerbation (mood depression as well as elevation) in those with a history of bipolar disorder during the late menopause transition and early postmenopause. ${ }^{52}$

\section{What symptoms commonly co-occur with depression in midlife women?}

Several common symptoms of the menopause transition and natural or surgical postmenopause (VMS, sleep and sexual disturbances, weight/energy changes, cognitive shifts, and urinary symptoms) co-occur and overlap with the presentation of depression during this stage. ${ }^{53}$ Depression itself may present with sleep, sexual, appetite, energy, and concentration difficulties. VMS and sleep disturbance are especially common and can be severe after surgical menopause. ${ }^{54,55}$ An evaluation of the co-occurrence of depressive symptoms and menopausal symptoms was performed via cluster analysis in a sample of 797 women with no history of MDD who were participating in the MSFlash trials. ${ }^{56}$ At baseline, there were two symptom clusters that included women with elevated depressive symptoms. In one cluster (14\% of the total sample), elevated depressive symptoms were clustered with high levels of insomnia, very low sleep quality and moderately high VMS. In a smaller cluster (7\% of the total sample), elevated depressive symptoms were clustered with elevated anxiety but minimally with other symptoms. In the cluster characterized by the highest level of VMS (11\% of the sample), depressive symptoms were low, indicating that depressive symptoms are not uniformly present, even when VMS are severe.

Because these same symptoms also may be secondary to menopause, it becomes difficult to parse out contributing etiologies, relative contributions of each etiology, and potential additive effects. ${ }^{53,57}$ In addition, symptoms unique to the menopause transition and postmenopause, including VMS and vaginal dryness, have the potential to magnify or complicate individual symptoms and global clinical experience of depressive disorders during this stage. ${ }^{58}$ Furthermore, depression may affect an individual's appraisal of the degree of bother from somatic symptoms commonly encountered during the menopause transition; thereby, further magnifying the effect of symptoms on quality of life. ${ }^{59}$

Vasomotor symptoms and sleep. The interrelationship between depressive symptoms, VMS, and sleep disturbances has been studied. The domino theory asserts that night sweats may be causally related to sleep disturbances that, in turn, are causally related to depressive symptoms. ${ }^{60}$ Subsequent studies have supported some aspects of this theory and questioned others. ${ }^{61}$ A study examining the effect of VMS on 
sleep via induction by a gonadotropin-releasing hormone agonist demonstrated a causal relationship between VMS and difficulty sleeping. ${ }^{62}$ In the POAS cohort, where all women were premenopausal at baseline, depressive symptoms were more likely to precede VMS in the menopause transition among women who had no experience of either symptom prior to the transition, findings that challenge the causal relationships of the domino theory as a universal explanation of the association between these symptoms. ${ }^{63}$ Experimental studies examining the relationship of mood with concurrent VMS and sleep disturbance have used gonadotropin-releasing hormone agonists to induce symptoms in healthy non-depressed women ${ }^{64}$ and, separately, have randomized women with a MDE to estrogen therapy or placebo. ${ }^{65,66}$ These studies have shown that for women without MDE, emergence of depressive symptoms on gonadotropin-releasing hormone agonists is linked with emergence of sleep disturbance, specifically sleep interruption, and with onset of nocturnal VMS, but not daytime VMS. ${ }^{64}$ In contrast, among women with MDE randomized to estrogen therapy, depressive symptoms improve in concert with improvement in sleep disturbance, but not in association with VMS. $^{66}$ Epidemiologic studies have similarly shown that VMS are linked with risk of developing subsequent depressive symptoms, ${ }^{24,26,65,66}$ but not MDE, ${ }^{23,26}$ although there is a statistical trend toward an association of VMS with subsequent emergence of first lifetime onset of MDD in $\mathrm{SWAN}^{23}$ and an early POAS study showed a significant association between VMS and new MDD onset. ${ }^{27}$ Taken together, these experimental and epidemiologic studies provide evidence that the relationship between depressive symptoms and VMS differs between those with and without MDE, with associations observed almost exclusively among those without MDE. ${ }^{67}$

Sleep disturbance has been linked with depression in midlife women. In women with VMS, the sleep characteristics that distinguish those with versus those without a depressive disorder include prolonged sleep-onset latency, reduced perceived quality of sleep, sleep efficiency, and overall total sleep duration. ${ }^{61}$ On the basis of these studies, it appears that VMS are causally related to difficulty sleeping. Difficulty sleeping, in turn, appears to be associated with depressive symptoms. ${ }^{64,66}$ Symptoms characteristic of the menopause transition and early natural or surgical postmenopause may overlap and compound symptoms common to depression.

Cognition: Depression and menopause itself may exert effects on concentration, thereby making it difficult to disentangle individual contributions. ${ }^{53,57}$ Subjective complaints of cognitive changes are common during the menopause transition; longitudinal studies from SWAN provide some objective validation to the subjective complaints because they demonstrate a transient impairment in learning during the menopause transition. ${ }^{68}$ Concurrent depressive and anxiety symptoms were associated with slower processing speed and anxiety was also associated with worse memory, but no symptom accounted for lower performance in late perimenopause compared to premenopause. ${ }^{69}$ Consistent with SWAN, the POAS demonstrated a decrease in learning and memory as women transitioned through the menopause even after accounting for age, depression, anxiety and other factors that can influence cognition. ${ }^{70}$ Midlife women with depression may also present with co-occurring cognitive slowing and deficits in encoding and thus have the potential of amplifying existing cognitive changes during the menopause transition. ${ }^{69,71}$
Fatigue: In addition, selected neurovegetative features of depression (decreased energy, increased appetite) may overlap with and compound subjective complaints of fatigue as well as weight increases commonly reported during and after the menopause transition. ${ }^{72}$

Sexual function: Genitourinary changes accompanying menopause may affect sexual function and desire. ${ }^{73}$ Decreased libido also may be a symptom of depression. ${ }^{74}$ The dual effect of depression and the menopause transition on sexual desire and performance may be additive, ${ }^{75}$ an effect that may be especially true for surgical menopause. ${ }^{76,77}$

Urinary incontinence: There is a small and inconsistent literature suggesting a bidirectional association between urinary incontinence and depression in midlife women. Prospective cohort studies have found depressive symptoms to be a risk factor for persistent urinary incontinence. ${ }^{78,79}$ Other cross-sectional studies have reported that postmenopausal women with urinary incontinence are more likely to have depressive and anxiety symptoms. ${ }^{80}$ In contrast, several other studies have not observed a clear link between depression and urinary incontinence in midlife women with depression. $^{22,23}$ The basis for this potential association is not understood but might be related to decreased serotonin levels in the central nervous system that have been correlated with increased urinary frequency and bladder contractions. ${ }^{81,82}$

\section{What are the unique psychosocial challenges associated with the menopause transition that might contribute to depressive symptoms?}

The psychosocial factors observed during the menopause transition and postmenopause may be unique to midlife. Older studies posit that depressive symptoms, previously termed "involutional melancholia," 83 arose from an "empty nest" phenomenon; namely, that women may be prone to depressive symptoms when children leave the home. ${ }^{84}$ This theory has since been refuted with empiric data which suggest an improvement in wellbeing in women when children leave the home and no effect of the return of adult children ("revolving door') on mood. ${ }^{85}$ Nonetheless, menopause may represent a uniquely challenging time for women. Many women face a series of stressors including but not exclusive to caring for aging parents, death of parents, medical illness in self and family, adjusting to emotional and physical sequelae of surgical menopause and other health issues that are common to this stage of life, children leaving the home, and changes in marital status. With the onset of childbirth at an increasingly later age, women are often faced with the dual responsibility of raising young children amid caring for aging parents while navigating their careers and ensuing challenges. These multiple demands are often faced without supports in place to identify or address the ensuing distress placed on a woman during this stage.

\section{What screening measures have been validated for assessing depression and depressive symptoms?}

Several general validated screening measures for clinical settings, including but not exclusive to the PHQ-9, may be used for categorical determination of mood disorder diagnoses during the menopause transition as they are in other populations. In research settings, questionnaires such as the Center for Epidemiological Studies Depression Scale (CES-D), as well as the Quick Inventory of Depressive Symptomatology-Self- 
Report, also may be helpful in capturing symptom severity and are predictive albeit not diagnostic of MDD during midlife. ${ }^{86,87}$ It is important to note that several symptoms common to the menopause transition (VMS, cognitive changes, sleep disturbances) may affect scoring. ${ }^{57}$ The HDRS is also commonly used in research studies, and is clinician administered. ${ }^{88}$ A menopause-specific mood disorder scale does not yet exist, but other menopause-specific validated symptom and qualityof-life (QOL) scales measuring more general parameters may be useful. The Menopause Rating Scale (MRS) incorporates a range of perimenopause measures including but not exclusive to mood, libido, and vaginal dryness. ${ }^{89}$ The MenopauseSpecific Quality-of-Life Scale (MENQOL) assesses and identifies psychological and somatic parameters that affect QOL during the menopause transition. ${ }^{90}$ Other commonly used scales include the Greene Climacteric Scale and the Utian Quality-of-Life Scale. ${ }^{91,92}$ Although these scales address domains of psychiatric symptoms, they do not distinguish distress from major depression or subsyndromal depression. Moreover, they also do not necessarily capture the duration of symptoms or the effect of mood disturbance on function. ${ }^{89,90}$

\section{Therapeutic Effects of Antidepressant Medications on Clinical Depression in Peri- and Postmenopausal Women}

What are the therapeutic effects of antidepressants on MDE in perimenopausal and postmenopausal women?

Two large randomized, double-blind, placebo-controlled trials examined the efficacy of desvenlafaxine for MDD in perimenopausal and postmenopausal women defined using STRAW criteria (see Table 4). ${ }^{93,94}$ Short-term treatment with $50 \mathrm{mg}$ and 100-200 mg doses of desvenlafaxine led to significant improvement in depressive symptoms compared with placebo. ${ }^{93,94}$ Post-hoc analyses of pooled data from these trials showed significant improvement with desvenlafaxine in both the perimenopausal and postmenopausal subgroups, including lower symptom burden and higher remission rates. ${ }^{95,96}$ To date, no other antidepressants have been studied in large randomized placebo-controlled trials of well-defined perimenopausal and postmenopausal women with MDD. There have been a number of small open-label studies of other antidepressants including selective serotonin reuptake inhibitors (SSRIs; citalopram, escitalopram, vortioxetine), serotoninnorepinephrine reuptake inhibitors (SNRIs; venlafaxine, duloxetine) and mirtazapine to treat MDD in perimenopausal and postmenopausal women that have demonstrated a positive effect on mood as well as VMS, sleep, anxiety, and pain. ${ }^{97-103}$ Bupropion, a norepinephrine-dopamine reuptake inhibitor (NDRI), is sometimes prescribed alone or in combination with an SSRI/SNRI to perimenopausal women because it does not lead to as much weight gain, sexual dysfunction, or sleepiness as SSRI/SNRIs. ${ }^{104}$ However, there are no RCTs of buproprion in perimenopausal women.

\section{Are there differences in efficacy between types of antidepressants in the treatment of peri- or postmenopausal women with MDD?}

A large randomized double-blind trial compared the SNRI desvenlafaxine and the SSRI escitalopram on MDD in

Table 4. Large Randomized Trials Examining the Efficacy of Antidepressants for Major Depressive Disorder in Well-Defined Perimenopausal and Postmenopausal Women

\begin{tabular}{|c|c|c|}
\hline Study & Design & Population \\
\hline $\begin{array}{l}\text { Kornstein } \\
\quad \text { et al. } 2010\end{array}$ & $\begin{array}{l}\text { Randomized } \\
\text { double-blind, } \\
\text { placebo-controlled } \\
\text { 8-week trial }\end{array}$ & $\begin{array}{l}387 \text { peri- and } \\
\text { postmenopausal } \\
\text { women (aged } \\
40-70 \text { years) } \\
\text { with MDD }\end{array}$ \\
\hline
\end{tabular}
Soares et al.
2010

Clayton et al. 2013

Kornstein et al. 2014

Kornstein et al. 2015
Randomized double-blind 8-week trial with 6-month continuation phase

Randomized double-blind, placebo-controlled 8-week trial

Post-hoc analysis of randomized double-blind, placebo-controlled 8-week trial

Pooled data from 2 randomized, double-blind, placebo- controlled 8-week trials
607 postmenopausal women (aged 40-70 years) with MDD

434 peri- and postmenopausal women (aged 40-70 years) with MDD

135 perimenopausal Desvenlafaxine and 291 postmen- $50 \mathrm{mg} / \mathrm{d}$ vs. opausal women placebo (aged 40-70 years) with MDD

252 perimenopausal and 546 postmenopausal women (age 40-70 years) with MDD

Medication

Desvenlafaxine (flexible dosing $100-200 \mathrm{mg} / \mathrm{d}$ with mean daily dose $162-176 \mathrm{mg} /$ d) vs. placebo

Desvenlafaxine 100-200 mg/d vs. escitalopram $10-20 \mathrm{mg} / \mathrm{d}$

Desvenlafaxine $50 \mathrm{mg} / \mathrm{d}$ vs. placebo

Desvenlafaxine (100-200 mg/d) for 8 weeks and Desvenlafaxine $(50 \mathrm{mg} / \mathrm{d})$ for 10 weeks

Results

Significant improvement in depressive symptoms (HAMD-17) with desvenlafaxine versus placebo; Response rate $=59 \%$ vs. $32 \%$, remission rate $=38 \%$ vs. $22 \%$; Effect evident as early as week 1

No significant differences between desvenlafaxine and escitalopram after 8 weeks or after 6 months continuation phase

Significant improvement in depressive symptoms (HAMD-17) with desvenlafaxine versus placebo; also significant benefits on pain and functional outcomes

Significant improvement in depressive symptoms in both peri- and postmenopausal subgroups with desvenlafaxine vs. placebo

Significant improvement in depressive symptoms (HAMD-17) and secondary outcomes (SDS, MRS) with desvenlafaxine vs. placebo in both peri- and postmenopausal women 
postmenopausal women defined using STRAW criteria; no significant difference in efficacy was seen after 8 weeks of acute phase treatment nor after 6 months of continuation phase treatment (see Table 4). ${ }^{105}$ These findings were in contrast to a previous analysis of a large pooled dataset by sex and age (using a cutoff of 50) comparing remission rates with venlafaxine, SSRIs, or placebo that found a significant advantage in remission rates favoring the SNRI venlafaxine over SSRIs in older women. ${ }^{106}$ Another post-hoc analysis of clinical trial data using age-defined menopause status showed no difference in the efficacy of the SNRI venlafaxine versus the SSRI fluoxetine in younger or older women. ${ }^{107}$ Similarly, a pooled analysis of open-label trials showed no differences in response rates to reboxetine, sertraline, or venlafaxine in older and younger women. ${ }^{108}$ Some studies have noted a superior effect of an SSRI over a tricyclic or norepinephrine reuptake inhibitor (NRI) in premenopausal women, but no such differences were found in postmenopausal women in those studies. ${ }^{109-111}$

\section{Does clinical response to antidepressants differ according to menopause status?}

Several studies have examined whether there are differences in antidepressant response in premenopausal versus postmenopausal women, all using age as a proxy for menopause status. In the pooled analysis of clinical trials of venlafaxine, SSRIs, and placebo discussed above, poorer response to SSRIs was noted in postmenopausal compared with premenopausal women, whereas response to venlafaxine did not differ by menopause status. ${ }^{106}$ Another pooled analysis showed no differences in antidepressant response to either bupropion or SSRIs by menopause status, ${ }^{112}$ nor did a large study of venlafaxine and fluoxetine. ${ }^{107}$ Like the Thase $2005^{106}$ study, several open-label studies have demonstrated relative resistance to SSRIs and other antidepressants in postmenopausal versus premenopausal women, ${ }^{113-115}$ whereas others did not find a difference by menopause status. ${ }^{11,116-118}$ Only one study examined menopause status as a predictor of depression recurrence during antidepressant treatment; rates of recurrence of MDD during treatment with venlafaxine or fluoxetine did not differ in pre-versus postmenopausal women. ${ }^{107}$

\section{Does estrogen therapy improve antidepressant response in peri- or postmenopausal women?}

Two post-hoc analyses of randomized placebo-controlled studies of SSRIs in older women with MDD found an interaction between use of concomitant estrogen therapy and antidepressant treatment effect, suggesting that estrogen may augment antidepressant response to SSRIs in postmenopausal depressed women. ${ }^{119,120}$ Two small open-label trials showed increased or accelerated response to SSRIs in postmenopausal depressed women who also took estrogen, ${ }^{121,122}$ whereas two other open-label studies showed no difference in response or remission rates in peri- or postmenopausal depressed women treated with SSRIs who were taking versus not taking estrogen. ${ }^{123,124}$ In the analysis of the large pooled dataset of trials of venlafaxine, SSRIs, and placebo discussed above, concomitant use of HT in the postmenopausal women eliminated the disparity in response rates to SSRIs in pre- versus postmenopausal women; HT did not affect response rates to venlafaxine. ${ }^{106}$ In a small double-blind placebo-controlled trial, estrogen aug- mentation improved antidepressant response in perimenopausal women with MDD in partial remission. ${ }^{125}$

\section{Effects of Hormone Therapy on Depression}

\section{Does HT have an effect on depressive disorders in perimenopausal women?}

At least four small studies-including two RCTs-have demonstrated the efficacy of estradiol for the management of depressive disorders (e.g., MDD, dysthymia or minor depression) during perimenopause (see Table 5). ${ }^{65,121,126,127}$ The two RCTS had similar designs and are considered of high quality because of the use of standardized tools to confirm the diagnosis of depression, the characterization of menopause staging using FSH levels and history of menstrual irregularity, and monitoring of treatment compliance with serum estradiol measurements. ${ }^{65,126}$ Antidepressant effects were well documented (reduction in CES-D, HDRS, and MADRS scores), and significant mood improvement was observed in those experiencing new-onset or recurrent depression in the presence or absence of concomitant VMS. Moreover, the antidepressant effects of estradiol persisted after a 4-week washout period, even after re-emergence of VMS and night sweats. ${ }^{126}$ There are no RCTs of combination estrogen plus progestogen for depression in perimenopausal women.

\section{Does hormone therapy have an effect on depressive disorders in postmenopausal women?}

Several small RCTs have examined the efficacy of HT on mood in postmenopausal women with depressive disorders and suggest that HT is not efficacious in this population. In an 8 -week study, both transdermal estradiol $(0.1 \mathrm{mg})$ and placebo improved depressive symptoms (HDRS scores or CES$\mathrm{D}$ scores) in late postmenopausal women $(n=57$; mean age $=67$ years; $\sim 16$ years after FMP) with mild-to-moderate depression. $^{128}$ In a 24 -week trial of 129 postmenopausal women $^{129}$ with minor to major depressive episode (mean age $=55$ years $)$ combination estradiol valerate $(2 \mathrm{mg} / \mathrm{d})$ plus dienogest $(2 \mathrm{mg} / \mathrm{d})$ significantly improved mood (HDRS) compared with placebo. However, the dropout rate was unusually high in both HT (33\%) and placebo groups (58\%). In an 8-week randomized, placebo-controlled trial of 72 periand postmenopausal women (mean age $=51$ years) with depression of mild to moderate severity and significant insomnia and VMS, transdermal estradiol $(0.05 \mathrm{mg} / \mathrm{d})$, zolpidem $(10 \mathrm{mg} / \mathrm{d})$, and placebo each improved depressive symptoms (MADRS scores) and there was no meaningful differences between active treatment groups and placebo. Overall improvement in mood was significantly correlated with an increase in serum estradiol over time (perimenopausal women only) and improvement in perceived sleep quality (peri- and postmenopausal women), but not to VMS or changes in objective measures of sleep. ${ }^{66}$ There are insufficient data on estrogen plus progestogen for depression in postmenopausal women to guide treatment choice.

New evidence indicates that certain women are particularly vulnerable to depressed mood following estrogen withdrawal. Asymptomatic postmenopausal women $(n=56)$ with history of perimenopausal depression were administered transdermal estradiol $(100 \mu \mathrm{g} / \mathrm{d})$ in an open-label fashion for three weeks and then were randomized to receive either transdermal estradiol or 
Table 5. Randomized Trials of Hormone Therapy for Depressed Peri- and Postmenopausal Women

\begin{tabular}{|c|c|c|c|c|c|}
\hline Authors & $\begin{array}{c}\text { Population studied } \\
\text { (Type, n) }\end{array}$ & Design & Intervention & $\begin{array}{l}\text { Outcome } \\
\text { measures }\end{array}$ & Key findings \\
\hline $\begin{array}{l}\text { Schmidt et al., } \\
2001\end{array}$ & $\begin{array}{l}\text { Perimenopause-related } \\
\text { depression }(n=31)\end{array}$ & $\begin{array}{l}\text { DB, PL Parallel } \\
\text { study followed } \\
\text { by crossover, } \\
\text { PL controlled }\end{array}$ & $\begin{array}{l}\text { ET (transdermal } \\
\text { E2), followed } \\
\text { by MPA }\end{array}$ & $\begin{array}{l}\text { HDRS, CES-D } \\
\text { scores }\end{array}$ & $\begin{array}{l}\text { ET led to significant } \\
\text { improvements in } \\
\text { depressive symptoms } \\
\text { (HDRS and CES-D } \\
\text { scores) }\end{array}$ \\
\hline $\begin{array}{l}\text { Soares et al., } \\
2001\end{array}$ & $\begin{array}{c}\text { Perimenopause-related } \\
\text { depression }(n=45)\end{array}$ & $\begin{array}{l}\text { DB, PL Parallel } \\
\text { study }\end{array}$ & $\begin{array}{l}\text { ET (transdermal } \\
\text { E2) }\end{array}$ & $\begin{array}{r}\text { MADRS } \\
\text { scores }\end{array}$ & $\begin{array}{l}\text { ET led to significant } \\
\text { improvements in } \\
\text { depressive symptoms } \\
\text { (MADRS scores) }\end{array}$ \\
\hline $\begin{array}{l}\text { Rudolph et al., } \\
2004\end{array}$ & $\begin{array}{l}\text { Postmenopausal women } \\
\text { with mild/moderate } \\
\text { depressive symptoms } \\
(n=129)\end{array}$ & $\begin{array}{l}\text { DB, PL Parallel } \\
\text { study }\end{array}$ & $\begin{array}{l}\text { EPT (oral E2 } \\
\text { valerate }+ \\
\text { progestin } \\
\text { [dienogest]) }\end{array}$ & HDRS scores & $\begin{array}{l}\text { EPT led to improvements } \\
\text { in HDRS scores; high } \\
\text { attrition rates in both } \\
\text { groups }\end{array}$ \\
\hline $\begin{array}{l}\text { Morrison } \\
\quad \text { et al., } 2004\end{array}$ & $\begin{array}{l}\text { Postmenopausal women } \\
\text { with depressive } \\
\text { disorders }(n=57)\end{array}$ & $\begin{array}{l}\text { DB, PL Parallel } \\
\text { study }\end{array}$ & $\begin{array}{l}\text { ET (transdermal } \\
\text { E2) followed } \\
\text { by MPA }\end{array}$ & $\begin{array}{l}\text { HDRS, CES-D } \\
\text { scores }\end{array}$ & $\begin{array}{l}\text { No differences with active } \\
\text { treatment (both groups } \\
\text { showed improvement) }\end{array}$ \\
\hline $\begin{array}{l}\text { Joffe et al., } \\
2011\end{array}$ & $\begin{array}{l}\text { Mixed peri- and post- } \\
\text { menopausal women } \\
\text { with depressive } \\
\text { symptoms, VMS and } \\
\text { insomnia }(n=72)\end{array}$ & $\begin{array}{l}\text { DB, PL Parallel } \\
\text { study }\end{array}$ & $\begin{array}{l}\text { ET (transdermal } \\
\text { E2), Zolpidem }\end{array}$ & $\begin{array}{l}\text { MADRS, BDI, } \\
\text { PSQI scores }\end{array}$ & $\begin{array}{l}\text { No significant differences } \\
\text { with respect to mood } \\
\text { changes between } \\
\text { treatment and PL groups }\end{array}$ \\
\hline
\end{tabular}

BDI, Beck Depression Inventory; CES-D, Center for Epidemiologic Studies-Depression Scale; DB-Double blind; EPT, estrogenprogestin therapy, E2, estradiol; ET, estrogen therapy; HDRS, Hamilton Depression Rating Scale; MADRS, Montgomery-Åsberg Depression Rating Scale; MPA, medroxyprogesterone acetate; PL, placebo; PSQI, Pittsburgh Sleep Quality Index.

placebo for 3 additional weeks in a double-blind fashion. ${ }^{130} \mathrm{Al}-$ though free of depressive symptoms during the open-label estradiol phase, women who were crossed over from estradiol to placebo-that is, who experienced estrogen withdrawalreported an increase in depressive symptoms (CES-D and HDRS), whereas those who remained on estradiol therapy continued to be asymptomatic. Hot flash severity and plasma estradiol levels were similar between treatment and placebo phases.

\section{Does HT prevent depressive symptoms during the menopausal transition?}

To date only one randomized trial has investigated the efficacy of HT in preventing the onset of significant depressive symptoms in euthymic perimenopausal and early postmenopausal women. ${ }^{131}$ A total of 172 euthymic perimenopausal or early postmenopausal women were randomly assigned to receive either transdermal estradiol $(0.1 \mathrm{mg} / \mathrm{d})$ plus intermittent oral micronized progesterone ( $200 \mathrm{mg} / \mathrm{d}$ for 12 days every 3 months) or placebo patches plus pills. After 12 months, women receiving active HT were significantly less likely to develop elevated depression scores compared with women receiving placebo (32.3\% vs. $17.3 \%)$. These effects were modified by stressful life events, with greater benefits for women with stressful life events in the preceding six months, and a suggestion that women in the early perimenopausal stage may have more benefit than women in other menopause stages. Unexpectedly, VMS and history of MDD (33\% of sample) did not modify the effect of HT on preventing depressive symptoms.

\section{Hormonal contraceptives in perimenopausal women}

For perimenopausal women, hormonal contraceptives provide contraceptive as well as non-contraceptive benefits, including restoring regular menses, decreasing dysmenorrhea, reducing heavy menstrual bleeding, and treating VMS. ${ }^{132} \mathrm{Al}-$ though these benefits have the potential to improve mood, there are no published randomized trials or open-label trials of hormonal contraceptives in women with clinical depression. The Food and Drug Administration (FDA) approved a 24/4 regimen of drospirenone $(3 \mathrm{mg})$ and ethinyl estradiol $(0.02 \mathrm{mg})$ pill for the treatment of premenstrual dysphoric disorder (PMDD). ${ }^{133,134} \mathrm{~A}$ combination pill that also includes levomefolate is also FDA approved for the treatment of PMDD. Neither formulation, however, has been studied in women with depression. Generally, for perimenopausal women, continuous oral contraceptive pills (OCPs) or cyclic OCPs with a low-dose estradiol patch during placebo week are used. During pill-free days, perimenopausal women can experience worsening of menopausal symptoms, so continuous oral contraceptive hormone use, which is effective in symptom control is generally preferred over cyclic with pill-free days. ${ }^{135}$ Although it has not been studied in depression, an alternative option that is used in the perimenopause is transdermal estrogen plus a levonorgestrel intrauterine system, which provides endometrial protection and contraception and decreases VMS in perimenopausal women. ${ }^{136}$

\section{Effect of Other Therapies on Depression and Depressive Symptoms in Midlife Women}

What nonpharmacologic therapies have at least preliminary evidence for menopause-related depressive disorders?

Cognitive-behavioral therapy $(C B T)$ is a time-limited psychotherapy to help patients assess and modify distorted, depression-promoting, automatic thoughts about themselves, their current situations, and their futures. These cognitive 
techniques are paired with behavioral interventions to combat passive disengagement from life activities. CBT has been shown to be effective for reducing symptoms of depression, preventing depressive relapses in the general population, ${ }^{137}$ and treating depressive symptoms in primary care settings. ${ }^{138}$ Practice guidelines have preferentially recommended antidepressant pharmacotherapy over psychotherapy for severe episodes of depression in general adult populations; however, recent evidence suggests that baseline depression severity may not moderate differences in antidepressant efficacy between CBT and antidepressant pharmacotherapy for adults with depression. ${ }^{139}$ Combining CBT and antidepressant pharmacotherapy may be more effective for reducing depressive symptoms, improving recovery rates, and increasing adherence to treatment than medication alone. ${ }^{140} \mathrm{CBT}$ also appears to be as effective as continuing antidepressant treatment for preventing relapses. ${ }^{141}$

Two clinical trials provide initial evidence that CBT improves depression related to the menopause. In the first study, 44 women outpatients (mean age $=49$ years, $52 \%$ perimenopausal, $48 \%$ premenopausal) who were not taking HT were randomly assigned to receive twice-weekly group CBT (16 sessions) or an undefined control condition. ${ }^{142}$ Group CBT, but not the control condition, led to a significant improvement in depressive symptoms (BDI) from baseline. Similar results were evident in analyses of perimenopausal women only. In a second study, individual CBT (16 sessions) was delivered to 353 women (mean age $=42$ years) who were not taking or were withdrawn from psychotropic medication. ${ }^{143}$ Classification of menopausal stage was defined according to non-validated criteria with 169 classified as premenopausal, 76 as perimenopausal based on age range (42-51.5 years) and at least one menstrual period reported within the year before trial entry, and the remaining 108 participants as postmenopausal. Overall, 93 participants $(55 \%)$ showed a positive treatment response defined as $50 \%$ or greater improvement in depressive symptoms (HDRS) from baseline, and rates did not differ by menopause status. Twenty $(26 \%)$ perimenopausal and $30(28 \%)$ postmenopausal participants achieved depressive symptom remission, defined as a HDRS total score 6 or less at study exit.

There is preliminary support that the core elements of CBT that have been shown to be efficacious in depression treatment in the general population may also apply to patients with depression related to the menopause transition. However, the lack of appropriate control conditions and lack of standardized criteria to define menopausal stage limit the data quality. Large, randomized trials of CBT specifically designed for women with depression related to menopause transition are needed. However, given the strong evidence base supporting individual or group CBT for depression in the general population, the relatively low risk of harms, and the preliminary evidence supporting these interventions in perimenopausal and postmenopausal women, CBT is a reasonable option for treatment of depression related to the menopause transition.

\section{What therapies are effective for depression in general but have not been studied in the menopause?}

Several therapies are recommended for depression in general but have not been studied in the menopause. These include the psychotherapies interpersonal therapy and mindfulness-based cognitive therapy (MBCT). Therapies recommended for treatment-resistant depression that have not been studied specifically for menopause-related depression include electroconvulsive therapy (ECT), transcranial magnetic stimulation (TMS), and vagus nerve stimulation. Similarly, light therapy for patients with seasonal affective disorder has not been studied specifically for women in the menopause transition. A Cochrane meta-analysis of clinical trials of exercise for the treatment of MDD in adults over 18 found that exercise reduces depression symptoms, but in high-quality studies, exercise confers only small benefits. ${ }^{144}$ A meta-analysis of clinical trials of exercise for depressive symptoms in midlife and older women without MDD found that exercise improved depressive symptoms. ${ }^{145}$

\section{Summary and Guidelines}

On the basis of the data, the expert panel makes the following recommendations for the evaluation and treatment of depression during the menopause transition.

\section{Epidemiology}

- The perimenopause is a window of vulnerability for the development of both depressive symptoms and major depressive episodes.

- The risk of depressive symptoms is elevated during the perimenopause even in women with no history of major depressive disorder.

- Most midlife women who experience a MDE during the perimenopause have experienced a prior episode of depression; therefore, the episode represents recurrence of their illness. First lifetime onset of MDD during this time is less common.

- Data are mixed about whether women who undergo surgical menopause are at increased or decreased risk for developing depression compared with women who transition through menopause naturally. However, recent large-scale studies show an elevated risk of depression in women following hysterectomy with and without oophorectomy. Women with primary ovarian insufficiency also have shown elevated rates of depression.

- Risk factors for depressive symptoms during the perimenopause include prior MDD, sociodemographic factors (e.g., younger age, black race, financial difficulties), psychosocial factors (adverse life events, low social support), menopause symptoms (VMS, sleep disturbance), anxiety symptoms, and reproductiverelated mood disturbance (e.g., postpartum and/or premenstrual depressive symptoms).

- Risk factors for MDD during the perimenopause include mental health factors (prior MDD, current use of antidepressants, anxiety, trait anxiety, premenstrual depressive symptoms), sociodemographic factors (black race, high BMI, younger age), psychosocial factors (upsetting life events, social isolation), and menopausal symptoms (especially sleep disturbance).

\section{Clinical presentation}

- Depression during midlife presents with classic depressive symptoms, commonly in combination with 
menopause-specific symptoms (i.e., VMS, sleep disturbance) and psychosocial challenges.

- Several common symptoms of the perimenopause (hot flashes, night sweats, sleep and sexual disturbances, weight/energy changes, cognitive shifts) complicate, co-occur, and overlap with the presentation of depression during this stage.

- Vasomotor symptoms are associated with depressive symptoms but not MDEs, except in women with first lifetime onset of a depressive episode during the perimenopause.

- Life stressors that are common for women at midlife (e.g., caring for children and parents, career and relationship shifts, aging, body changes) and personal/ family illness can adversely affect mood but "empty nest" and "revolving door" have little enduring effect.

\section{Assessment and diagnosis}

- Evaluation includes identification of menopause stage, assessment of co-occurring and overlapping menopause and psychiatric symptoms, consideration of psychosocial risk factors, appreciation of the differential diagnosis, and use of scales to aid in disentangling symptoms and distinguishing diagnoses.

- Women with past MDEs (not necessarily hormone related) and women with severe depressive symptoms and/or suicidal ideation should always be evaluated for a mood disorder.

- The differential diagnosis of depression during the perimenopause includes MDD, subsyndromal depression, adjustment disorder, psychological distress, bereavement, depressive episodes associated with bipolar disorder, and general medical causes of depression.

- A menopause-specific mood-disorder scale does not exist; however, several general validated screening measures (e.g., PHQ-9) may be used for categorical determination of mood disorder diagnoses. Validated menopause symptom and health-related quality of life scales (e.g., MRS, MENQOL, Greene Climacteric Scale, Utian Quality-of-Life Scale) include mood items and may be useful in clarifying the contribution of menopause-related symptoms.

\section{Treatment of MDD with antidepressants and psychotherapy}

- Proven therapeutic options for depression (i.e., antidepressants, CBT, and other psychotherapies) should remain as front-line antidepressant treatments for MDEs during the perimenopause.

- Existing data on various SSRI and SNRI antidepressants (including citalopram, desvenlafaxine, duloxetine, escitalopram, fluoxetine, sertraline, and venlafaxine) suggest good efficacy and tolerability at usual doses. In women with a history of MDD, a prior adequate response to a particular antidepressant should guide treatment selection when MDD recurs during midlife years. Only desvenlafaxine has been studied and proven efficacious in large randomized placebo-controlled trials of welldefined peri-and postmenopausal depressed women.
- Selection of antidepressants during the perimenopause should consider the woman's prior antidepressant trials and responses, available data on efficacy and tolerability in this specific population, management of challenging adverse effects (e.g., sexual dysfunction, weight changes) and safety (e.g., drug-drug interactions), given the likelihood of concomitant use of other medications during this stage of life.

- In addition to their efficacy in treating MDD, many antidepressants (SSRIs and SNRIs) also improve menopause-related complaints (e.g., VMS, pain).

- Clinicians should also consider treating co-occurring sleep disturbance and night sweats as part of treatment for menopause-related depression.

\section{Estrogen therapy}

- There is some evidence that ET has antidepressant effects of similar magnitude to that observed with classic antidepressant agents when administered to depressed perimenopausal women with or without concomitant VMS.

- Estrogen therapy is ineffective as a treatment for depressive disorders in postmenopausal women. Such evidence suggests a possible window of opportunity for the effective use of ET for the management of depressive disorders during the perimenopause.

- There is some evidence that ET enhances mood and improves well-being in non-depressed perimenopausal women.

- Hormonal contraceptives-particularly when used continuously-have shown some benefits for mood regulation and may improve depressive symptoms in women approaching menopause.

- Transdermal estradiol with intermittent micronized progesterone may prevent the onset of depressive symptoms in euthymic perimenopausal women, but the evidence is not sufficient to recommend estrogen-based therapies for preventing depression in asymptomatic peri- or postmenopausal women and the risks and benefits must be weighed.

- Estrogen-based therapies may augment clinical response to antidepressants in midlife and older women but their use should be considered with caution (i.e., preferably when also indicated for other concurrent conditions such as VMS).

- Most studies on HT for the treatment of depression examined the effects of unopposed estrogen. Data on combined HT (estrogen plus progestogen) or for different progestogens are sparse and inconclusive.

- Estrogen is not FDA approved to treat mood disturbance.

\section{Alternative therapies}

- The available evidence is insufficient for recommending any botanical or complementary/alternative approaches for treating depression related to the perimenopause.

- It is reasonable to recommend exercise in peri- and postmenopausal women with depression, particularly when used in combination with recommended psychotherapies and pharmacotherapies. 


\section{Acknowledgments}

The authors would like to thank Dr. Nicole Jaff for her helpful suggestions and careful review of the manuscript.

\section{Author Disclosure Statement}

Dr. Maki has received speaking honoraria from Mylan. Dr. Kornstein has research support from Marinus Pharmaceuticals, Palatin Technologies, Pfizer, and Takeda Pharmaceuticals, as well as consulting fees from Alkermes, AMAG Pharmaceuticals, Lilly, and Marinus Pharmaceuticals. Dr. Joffe has received grants from Merck and Pfizer, as well as consulting fees from KaNDy, Merck, and Sojournix. Dr. Cohen has received Research Support from the National Pregnancy Registry for Atypical Antipsychotics, Alkermes Biopharmaceuticals, Forest/Actavis Pharmaceuticals, Otsuka Pharmaceuticals, Sunovion Pharmaceuticals, Inc, Teva Pharmaceuticals, the Brain \& Behavior Research Foundation, JayMac Pharmaceuticals, SAGE Therapeutics, and Takeda/Lundbeck Pharmaceuticals, as well as consultant fees from Alkermes Biopharmaceuticals. Dr. Soares has received honoraria as a consultant for Bayer, Lundbeck, Otsuka and Pfizer. He has also received grants from the Ontario Brain Institute (OBI) and the Ontario Ministry of Technology, Innovation and Science. Drs. Bromberger, Freeman, Athappilly, Bobo, Rubin, and Koleva have no conflicts to disclose.

\section{References}

1. Maki PM, Freeman EW, Greendale GA, et al. Summary of the National Institute on Aging-sponsored conference on depressive symptoms and cognitive complaints in the menopausal transition. Menopause 2010;17:815-822.

2. Soares CN, Maki PM. Menopausal transition, mood, and cognition: an integrated view to close the gaps. Menopause 2010;17:812-814.

3. Steiner M. Female-specific mood disorders. Clin Obstet Gynecol 1992;35:599-611.

4. Arpels JC. The female brain hypoestrogenic continuum from the premenstrual syndrome to menopause. A hypothesis and review of supporting data. J Reprod Med 1996;41:633-639.

5. Rubinow DR, Schmidt PJ, Roca CA. Estrogen-serotonin interactions: implications for affective regulation. Biological Psychiatry 1998;44: 839-850.

6. Lokuge S, Frey BN, Foster JA, Soares CN, Steiner M. Depression in women: windows of vulnerability and new insights into the link between estrogen and serotonin. J Clin Psychiatry 2011;72:e1563-e1569.

7. Wittchen HU, Becker E, Lieb R, Krause P. Prevalence, incidence and stability of premenstrual dysphoric disorder in the community. Psychol Med 2002;32:119-132.

8. Bloch M, Rotenberg N, Koren D, Klein E. Risk factors for early postpartum depressive symptoms. Gen Hosp Psychiatry 2006;28:3-8.

9. Yonkers KA, O'Brien PM, Eriksson E. Premenstrual syndrome. Lancet 2008;371:1200-1210.

10. The 2017 hormone therapy position statement of The North American Menopause Society. Menopause 2017; 24:728-753.

11. Nonhormonal management of menopause-associated vasomotor symptoms: 2015 position statement of The North American Menopause Society. Menopause 2015;22:11551172.
12. Gelenberg AJ, Freeman MP, Markowitz JC, et al. Practice guideline for the treatment of patients with major depressive disorder third edition. Am J Psychiatry 2010; 167:1.

13. Harlow SD, Gass M, Hall JE, et al. Executive summary of the Stages of Reproductive Aging Workshop p 10: addressing the unfinished agenda of staging reproductive aging. Menopause 2012;19:387-395.

14. Bromberger JT, Matthews KA, Schott LL, et al. Depressive symptoms during the menopausal transition: the Study of Women's Health Across the Nation (SWAN). J Affect Disord 2007;103:267-272.

15. Rubinow DR, Johnson SL, Schmidt PJ, Girdler S, Gaynes B. Efficacy of Estradiol in Perimenopausal Depression: So Much Promise and So Few Answers. Depress Anxiety 2015;32:539-549.

16. Bromberger JT, Harlow S, Avis N, Kravitz HM, Cordal A. Racial/ethnic differences in the prevalence of depressive symptoms among middleaged women: The Study of Women's Health Across the Nation (SWAN). Am J Public Health 2004;94:1378-1385.

17. Brown JP, Gallicchio L, Flaws JA, Tracy JK. Relations among menopausal symptoms, sleep disturbance and depressive symptoms in midlife. Maturitas 2009;62:184189.

18. Lin HL, Hsiao MC, Liu YT, Chang CM. Perimenopause and incidence of depression in midlife women: a population-based study in Taiwan. Climacteric 2013;16: 381-386.

19. Maki PM, Rubin LH, Cohen M, et al. Depressive symptoms are increased in the early perimenopausal stage in ethnically diverse human immunodeficiency virus-infected and human immunodeficiency virusuninfected women. Menopause 2012; 19:1215-1223.

20. Timur S, Sahin NH. The prevalence of depression symptoms and influencing factors among perimenopausal and postmenopausal women. Menopause 2010;17:545551.

21. Mauas V, Kopala-Sibley DC, Zuroff DC. Depressive symptoms in the transition to menopause: the roles of irritability, personality vulnerability, and self-regulation. Arch Womens Ment Health 2014;17:279-289.

22. Bromberger JT, Kravitz HM, Chang YF, Cyranowski JM, Brown C, Matthews KA. Major depression during and after the menopausal transition: Study of Women's Health Across the Nation (SWAN). Psychol Med 2011;41:18791888.

23. Bromberger JT, Schott L, Kravitz HM, Joffe H. Risk factors for major depression during midlife among a community sample of women with and without prior major depression: are they the same or different? Psychol Med 2015;45:1653-1664.

24. Bromberger JT, Schott LL, Kravitz HM, et al. Longitudinal change in reproductive hormones and depressive symptoms across the menopausal transition: results from the Study of Women's Health Across the Nation (SWAN). Arch Gen Psychiatry 2010;67:598-607.

25. Freeman EW, Sammel MD, Boorman DW, Zhang R. Longitudinal pattern of depressive symptoms around natural menopause. JAMA Psychiatry 2014;71:36-43.

26. Freeman EW, Sammel MD, Lin H, Nelson DB. Associations of hormones and menopausal status with depressed mood in women with no history of depression. Arch Gen Psychiatry 2006;63:375-382. 
27. Freeman EW, Sammel MD, Liu L, Gracia CR, Nelson DB, Hollander L. Hormones and menopausal status as predictors of depression in women in transition to menopause. Arch Gen Psychiatry 2004;61:62-70.

28. Morrison MF, Freeman EW, Lin H, Sammel MD. Higher DHEA-S (dehydroepiandrosterone sulfate) levels are associated with depressive symptoms during the menopausal transition: results from the PENN Ovarian Aging Study. Arch Womens Ment Health 2011;14: 375-382.

29. Woods NF, Smith-DiJulio K, Percival DB, Tao EY, Mariella A, Mitchell S. Depressed mood during the menopausal transition and early postmenopause: observations from the Seattle Midlife Women's Health Study. Menopause 2008;15:223-232.

30. Cohen LS, Soares CN, Vitonis AF, Otto MW, Harlow BL. Risk for new onset of depression during the menopausal transition: the Harvard study of moods and cycles. Arch Gen Psychiatry 2006;63:385-390.

31. Harlow BL, MacLehose RF, Smolenski DJ, et al. Disparate rates of newonset depression during the menopausal transition in 2 communitybased populations: real, or really wrong? Am J Epidemiol 2013;177: 1148-1156.

32. Bromberger JT, Kravitz HM, Matthews K, Youk A, Brown C, Feng W. Predictors of first lifetime episodes of major depression in midlife women. Psychol Med 2009; 39:55-64.

33. Darwish M, Atlantis E, Mohamed-Taysir T. Psychological outcomes after hysterectomy for benign conditions: a systematic review and metaanalysis. Eur J Obstet Gynecol Reprod Biol 2014;174:5-19.

34. Chou $\mathrm{PH}$, Lin $\mathrm{CH}$, Cheng $\mathrm{C}$, et al. Risk of depressive disorders in women undergoing hysterectomy: A population-based follow-up study. J Psychiatr Res 2015; 68:186-191.

35. Wilson L, Pandeya N, Byles J, Mishra G. Hysterectomy and incidence of depressive symptoms in midlife women: the Australian Longitudinal Study on Women's Health. Epidemiol Psychiatr Sci 2017;1-12.

36. Rocca WA, Grossardt BR, Geda YE, et al. Long-term risk of depressive and anxiety symptoms after early bilateral oophorectomy. Menopause 2008;15:1050-1059.

37. Gibson CJ, Joffe H, Bromberger JT, et al. Mood symptoms after natural menopause and hysterectomy with and without bilateral oophorectomy among women in midlife. Obstet Gynecol 2012;119: 935-941.

38. Sherwin BB, Gelfand MM. Sex steroids and affect in the surgical menopause: a double-blind, cross-over study. Psychoneuroendocrinology 1985;10:325-335.

39. European Society for Human R, Embryology Guideline Group on POIWebber L, et al. ESHRE Guideline: management of women with premature ovarian insufficiency. Hum Reprod 2016;31:926-937.

40. Schmidt PJ, Luff JA, Haq NA, et al. Depression in women with spontaneous $46, \mathrm{XX}$ primary ovarian insufficiency. J Clin Endocrinol Metab 2011;96:E278-E287.

41. Liao KL, Wood N, Conway GS. Premature menopause and psychological well-being. J Psychosom Obstet Gynaecol 2000;21:167-174.

42. Singer D, Mann E, Hunter MS, Pitkin J, Panay N. The silent grief: psychosocial aspects of premature ovarian failure. Climacteric 2011; 14:428-437.

43. Dennerstein L, Guthrie JR, Clark M, Lehert P, Henderson VW. A population-based study of depressed mood in middle-aged, Australian-born women. Menopause 2004; 11:563-568.

44. Schmidt PJ, Haq N, Rubinow DR. A longitudinal evaluation of the relationship between reproductive status and mood in perimenopausal women. Am J Psychiatry 2004; 161:2238-2244.

45. McKinlay SM, Brambilla DJ, Posner JG. The normal menopause transition. Am J Hum Biol 1992;4:37-46.

46. Kornstein SG, Young EA, Harvey AT, et al. The influence of menopause status and postmenopausal use of hormone therapy on presentation of major depression in women. Menopause 2010;17:828-839.

47. Harsh V, Meltzer-Brody S, Rubinow DR, Schmidt PJ. Reproductive aging, sex steroids, and mood disorders. Harv Rev Psychiatry 2009; 17:87-102.

48. Bromberger JT, Meyer PM, Kravitz HM, et al. Psychologic distress and natural menopause: a multiethnic community study. Am J Public Health 2001;91:1435-1442.

49. Shifren JL, Avis NE. Surgical menopause: effects on psychological well-being and sexuality. Menopause 2007; 14:586-591.

50. Association AP. Diagnostic and statistical manual of mental disorders (DSM-51). American Psychiatric Pub; 2013.

51. Freeman EW, Sammel MD, Lin H, Gracia CR, Kapoor S. Symptoms in the menopausal transition: hormone and behavioral correlates. Obstet Gynecol 2008;111:127-136.

52. Marsh WK, Gershenson B, Rothschild AJ. Symptom severity of bipolar disorder during the menopausal transition. Int J Bipolar Disord 2015;3:35.

53. Soares CN, Taylor V. Effects and management of the menopausal transition in women with depression and bipolar disorder. J Clin Psychiatry 2007;68 (Suppl 9):16-21.

54. Kravitz HM, Ganz PA, Bromberger J, Powell LH, SuttonTyrrell K, Meyer PM. Sleep difficulty in women at midlife: a community survey of sleep and the menopausal transition. Menopause 2003;10:19-28.

55. Wilson LF, Pandeya N, Byles J, Mishra GD. Hot flushes and night sweats symptom profiles over a 17-year period in mid-aged women: The role of hysterectomy with ovarian conservation. Maturitas 2016;91:1-7.

56. Woods NF, Hohensee C, Carpenter JS, et al. Symptom clusters among MsFLASH clinical trial participants. Menopause 2016;23:158-165.

57. Soares CN. Mood disorders in midlife women: understanding the critical window and its clinical implications. Menopause 2014;21:198-206.

58. Joffe H, Soares CN, Cohen LS. Assessment and treatment of hot flushes and menopausal mood disturbance. Psychiatr Clin North Am 2003;26: 563-580.

59. Seritan AL, Iosif AM, Park JH, DeatherageHand D, Sweet RL, Gold EB. Self-reported anxiety, depressive, and vasomotor symptoms: a study of perimenopausal women presenting to a specialized midlife assessment center. Menopause 2010;17:410-415.

60. Campbell S, Whitehead M. Oestrogen therapy and the menopausal syndrome. Clin Obstet Gynaecol 1977;4:3147.

61. Joffe H, Soares CN, Thurston RC, White DP, Cohen LS, Hall JE. Depression is associated with worse objectively and subjectively measured sleep, but not more frequent awakenings, in women with vasomotor symptoms. Menopause 2009;16:671-679. 
62. Joffe H, Crawford S, Economou N, et al. A gonadotropinreleasing hormone agonist model demonstrates that nocturnal hot flashes interrupt objective sleep. Sleep 2013;36: 1977-1985.

63. Freeman EW, Sammel MD, Lin H. Temporal associations of hot flashes and depression in the transition to menopause. Menopause 2009;16: 728-734.

64. Joffe H, Crawford SL, Freeman MP, et al. Independent Contributions of Nocturnal Hot Flashes and Sleep Disturbance to Depression in Estrogen-Deprived Women. J Clin Endocrinol Metab 2016;101: 3847-3855.

65. Schmidt PJ, Nieman L, Danaceau MA, et al. Estrogen replacement in perimenopause-related depression: a preliminary report. Am J Obstet Gynecol 2000;183: 414-420.

66. Joffe H, Petrillo LF, Koukopoulos A, et al. Increased estradiol and improved sleep, but not hot flashes, predict enhanced mood during the menopausal transition. J Clin Endocrinol Metab 2011;96: E1044-E1054.

67. Worsley R, Bell R, Kulkarni J, Davis SR. The association between vasomotor symptoms and depression during perimenopause: a systematic review. Maturitas 2014;77: 111-117.

68. Greendale GA, Huang MH, Wight RG, et al. Effects of the menopause transition and hormone use on cognitive performance in midlife women. Neurology 2009;72:1850 1857.

69. Greendale GA, Wight RG, Huang MH, et al. Menopauseassociated symptoms and cognitive performance: results from the study of women's health across the nation. Am J Epidemiol 2010;171:1214-1224.

70. Epperson CN, Sammel MD, Freeman EW. Menopause effects on verbal memory: findings from a longitudinal community cohort. J Clin Endocrinol Metab 2013;98: 3829-3838.

71. Zakzanis KK, Leach L, Kaplan E. On the nature and pattern of neurocognitive function in major depressive disorder. Neuropsychiatry Neuropsychol Behav Neurol 1998;11:111-119.

72. Baune BT, Stuart M, Gilmour A, Wersching H, Arolt V, Berger K. Moderators of the relationship between depression and cardiovascular disorders: a systematic review. Gen Hosp Psychiatry 2012;34:478-492.

73. Portman DJ, Gass ML, Vulvovaginal Atrophy Terminology Consensus Conference P. Genitourinary syndrome of menopause: new terminology for vulvovaginal atrophy from the International Society for the Study of Women's Sexual Health and the North American Menopause Society. Menopause 2014;21:1063-1068.

74. Derogatis LR, Burnett AL. The epidemiology of sexual dysfunctions. J Sex Med 2008;5:289-300.

75. Prairie BA, Wisniewski SR, Luther J, et al. Symptoms of depressed mood, disturbed sleep, and sexual problems in midlife women: crosssectional data from the Study of Women's Health Across the Nation. J Womens Health (Larchmt) 2015;24:119-126.

76. Graziottin A. Menopause and sexuality: key issues in premature menopause and beyond. Ann N Y Acad Sci 2010;1205:254-261.

77. Madalinska JB, van Beurden M, Bleiker EM, et al. The impact of hormone replacement therapy on menopausal symptoms in younger high-risk women after prophylactic salpingo-oophorectomy. J Clin Oncol 2006;24:35763582.
78. Maserejian NN, Minassian VA, Chen S, Hall SA, McKinlay JB, Tennstedt SL. Treatment status and risk factors for incidence and persistence of urinary incontinence in women. Int Urogynecol J 2014;25:775-782.

79. Devore EE, Minassian VA, Grodstein F. Factors associated with persistent urinary incontinence. Am J Obstet Gynecol 2013;209:145e1-6.

80. Cagnacci A, Palma F, Carbone MM, Grandi G, Xholli A. Association between urinary incontinence and climacteric symptoms in postmenopausal women. Menopause 2017; 24:77-84.

81. Lai HH, Shen BX, Rawal A, Vetter J. The relationship between depression and overactive bladder/urinary incontinence symptoms in the clinical $\mathrm{OAB}$ population. Bmc Urology 2016;16:60.

82. de Groat WC. Influence of central serotonergic mechanisms on lower urinary tract function. Urology 2002;59: 30-36.

83. Kraepelin E. Psychiatrie; ein Lehrbuch für Studierende und Ärzte, 8., vollständig umgearb. Aufl. ed. Leipzig: Barth; 1909.

84. Harkins EB. Effects of Empty Nest Transition on SelfReport of Psychological and Physical Well-Being. J Marriage Fam 1978;40: 549-556.

85. Dennerstein L, Dudley E, Guthrie J. Empty nest or revolving door? A prospective study of women's quality of life in midlife during the phase of children leaving and reentering the home. Psychol Med 2002;32: 545-550.

86. Knight RG, Williams S, McGee R, Olaman S. Psychometric properties of the Centre for Epidemiologic Studies Depression Scale (CES-D) in a sample of women in middle life. Behav Res Ther 1997;35: 373-380.

87. Reilly TJ, MacGillivray SA, Reid IC, Cameron IM. Psychometric properties of the 16-item Quick Inventory of Depressive Symptomatology: a systematic review and meta-analysis. J Psychiatr Res 2015;60:132-140.

88. Hamilton M. A rating scale for depression. J Neurol Neurosurg Psychiatry 1960;23:56-62.

89. Heinemann LA, Potthoff P, Schneider HP. International versions of the Menopause Rating Scale (MRS). Health Qual Life Outcomes 2003;1:28.

90. Hilditch JR, Lewis J, Peter A, et al. A menopause-specific quality of life questionnaire: development and psychometric properties. Maturitas 2008;61:107-121.

91. Greene JG. Factor Analytic Study of Climacteric Symptoms. J Psychosom Res 1976;20:425-430.

92. Utian WH, Janata JW, Kingsberg SA, Schluchter M, Hamilton JC. The Utian Quality of Life (UQOL) Scale: development and validation of an instrument to quantify quality of life through and beyond menopause. Menopause 2002;9:402-410.

93. Kornstein SG, Jiang Q, Reddy S, Musgnung JJ, GuicoPabia CJ. Shortterm efficacy and safety of desvenlafaxine in a randomized, placebocontrolled study of perimenopausal and postmenopausal women with major depressive disorder. J Clin Psychiatry 2010;71:1088-1096.

94. Clayton AH, Kornstein SG, Dunlop BW, et al. Efficacy and safety of desvenlafaxine $50 \mathrm{mg} / \mathrm{d}$ in a randomized, placebo-controlled study of perimenopausal and postmenopausal women with major depressive disorder. J Clin Psychiatry 2013;74:1010-1017.

95. Kornstein SG, Clayton AH, Bao W, Guico-Pabia CJ. A pooled analysis of the efficacy of desvenlafaxine for the treatment of major depressive disorder in perimenopausal 
and postmenopausal women. J Womens Health (Larchmt) 2015;24:281-290.

96. Kornstein SG, Clayton A, Bao W, Guico-Pabia CJ. Post hoc analysis of the efficacy and safety of desvenlafaxine $50 \mathrm{mg} /$ day in a randomized, placebo-controlled study of perimenopausal and postmenopausal women with major depressive disorder. Menopause 2014;21:799-806.

97. Joffe H, Groninger H, Soares CN, Nonacs R, Cohen LS. An open trial of mirtazapine in menopausal women with depression unresponsive to estrogen replacement therapy. J Womens Health Gend Based Med 2001;10:999-1004.

98. Joffe H, Soares CN, Petrillo LF, et al. Treatment of depression and menopause-related symptoms with the serotonin-norepinephrine reuptake inhibitor duloxetine. J Clin Psychiatry 2007;68:943-950.

99. Soares CN, Poitras JR, Prouty J, Alexander AB, Shifren JL, Cohen LS. Efficacy of citalopram as a monotherapy or as an adjunctive treatment to estrogen therapy for perimenopausal and postmenopausal women with depression and vasomotor symptoms. J Clin Psychiatry 2003;64: 473-479.

100. Soares CN, Arsenio H, Joffe H, et al. Escitalopram versus ethinyl estradiol and norethindrone acetate for symptomatic peri- and postmenopausal women: impact on depression, vasomotor symptoms, sleep, and quality of life. Menopause 2006;13:780-786.

101. Ladd CO, Newport DJ, Ragan KA, Loughhead A, Stowe $\mathrm{ZN}$. Venlafaxine in the treatment of depressive and vasomotor symptoms in women with perimenopausal depression. Depress Anxiety 2005;22: 94-97.

102. Freeman MP, Hill R, Brumbach BH. Escitalopram for perimenopausal depression: an open-label pilot study. J Womens Health (Larchmt) 2006;15:857-861.

103. Freeman MP, Cheng LJ, Moustafa D, et al. Vortioxetine for major depressive disorder, vasomotor, and cognitive symptoms associated with the menopausal transition. Ann Clin Psychiatry 2017;29:249-257.

104. Serretti A, Chiesa A. Treatment-emergent sexual dysfunction related to antidepressants: a meta-analysis. J Clin Psychopharmacol 2009;29:259- 266.

105. Soares CN, Thase ME, Clayton A, et al. Desvenlafaxine and escitalopram for the treatment of postmenopausal women with major depressive disorder. Menopause 2010; 17:700-711.

106. Thase ME, Entsuah R, Cantillon M, Kornstein SG. Relative antidepressant efficacy of venlafaxine and SSRIs: sex-age interactions. J Womens Health (Larchmt) 2005; 14:609-616.

107. Kornstein SG, Pedersen RD, Holland PJ, et al. Influence of sex and menopausal status on response, remission, and recurrence in patients with recurrent major depressive disorder treated with venlafaxine extended release or fluoxetine: analysis of data from the PREVENT study. J Clin Psychiatry 2014;75:62-68.

108. Eker SS, Kirli S, Akkaya C, Cangur S, Sarandol A. Are there differences between serotonergic, noradrenergic and dual acting antidepressants in the treatment of depressed women? World J Biol Psychiatry 2009; 10:400-408.

109. Kornstein SG, Schatzberg AF, Thase ME, et al. Gender differences in treatment response to sertraline versus imipramine in chronic depression. Am J Psychiatry 2000; 157:1445-1452.

110. Martenyi F, Dossenbach M, Mraz K, Metcalfe S. Gender differences in the efficacy of fluoxetine and maprotiline in depressed patients: a double-blind trial of antidepressants with serotonergic or norepinephrinergic reuptake inhibition profile. Eur Neuropsychopharmacol 2001; 11:227-232.

111. Vermeiden M, van den Broek WW, Mulder PG, Birkenhager TK. Influence of gender and menopausal status on antidepressant treatment response in depressed inpatients. J Psychopharmacol 2010;24:497-502.

112. Papakostas GI, Kornstein SG, Clayton AH, et al. Relative antidepressant efficacy of bupropion and the selective serotonin reuptake inhibitors in major depressive disorder: gender-age interactions. Int Clin Psychopharmacol 2007; 22:226-229.

113. Grigoriadis S, Kennedy SH, Bagby RM. A comparison of antidepressant response in younger and older women. $\mathrm{J}$ Clin Psychopharmacol 2003;23:405-407.

114. Pinto-Meza A, Usall J, Serrano-Blanco A, Suarez D, Haro JM. Gender differences in response to antidepressant treatment prescribed in primary care. Does menopause make a difference? J Affect Disord 2006;93: 53-60.

115. Pae CU, Mandelli L, Kim TS, et al. Effectiveness of antidepressant treatments in pre-menopausal versus postmenopausal women: a pilot study on differential effects of sex hormones on antidepressant effects. Biomed Pharmacother 2009;63:228-235.

116. Quitkin FM, Stewart JW, McGrath PJ, et al. Are there differences between women's and men's antidepressant responses? Am J Psychiatry 2002;159:1848-1854.

117. Parker G, Parker K, Austin MP, Mitchell P, Brotchie H. Gender differences in response to differing antidepressant drug classes: two negative studies. Psychol Med 2003;33: 1473-1477.

118. Cassano P, Soares CN, Cusin C, Mascarini A, Cohen LS, Fava M. Antidepressant response and well-being in pre-, peri- and postmenopausal women with major depressive disorder treated with fluoxetine. Psychother Psychosom 2005;74:362-365.

119. Schneider LS, Small GW, Hamilton SH, Bystritsky A, Nemeroff CB, Meyers BS. Estrogen replacement and response to fluoxetine in a multicenter geriatric depression trial. Fluoxetine Collaborative Study Group. Am J Geriatr Psychiatry 1997;5:97-106.

120. Schneider LS, Small GW, Clary CM. Estrogen replacement therapy and antidepressant response to sertraline in older depressed women. Am J Geriatr Psychiatry 2001;9: 393-399.

121. Rasgon NL, Altshuler LL, Fairbanks L. Estrogenreplacement therapy for depression. Am J Psychiatry 2001; 158:1738.

122. Zanardi R, Rossini D, Magri L, Malaguti A, Colombo C, Smeraldi E. Response to SSRIs and role of the hormonal therapy in post-menopausal depression. Eur Neuropsychopharmacol 2007;17:400-405.

123. Amsterdam J, Garcia-Espana F, Fawcett J, et al. Fluoxetine efficacy in menopausal women with and without estrogen replacement. J Affect Disord 1999;55:11-17.

124. Kornstein SG, Toups M, Rush AJ, et al. Do Menopausal Status and Use of Hormone Therapy Affect Antidepressant Treatment Response? Findings from the Sequenced Treatment Alternatives to Relieve Depression (STAR_D) Study. J Womens Health (Larchmt) 2013;22:121-131.

125. Morgan ML, Cook IA, Rapkin AJ, Leuchter AF. Estrogen augmentation of antidepressants in perimenopausal depression: a pilot study. J Clin Psychiatry 2005;66:774780 . 
126. Soares CN, Almeida OP, Joffe H, Cohen LS. Efficacy of estradiol for the treatment of depressive disorders in perimenopausal women: a doubleblind, randomized, placebocontrolled trial. Arch Gen Psychiatry 2001;58:529-534.

127. Cohen LS, Soares CN, Poitras JR, Prouty J, Alexander $\mathrm{AB}$, Shifren JL. Short-term use of estradiol for depression in perimenopausal and postmenopausal women: a preliminary report. Am J Psychiatry 2003; 160:1519-1522.

128. Morrison MF, Kallan MJ, Ten Have T, Katz I, Tweedy K, Battistini M. Lack of efficacy of estradiol for depression in postmenopausal women: a randomized, controlled trial. Biol Psychiatry 2004;55:406-412.

129. Rudolph I, Palombo-Kinne E, Kirsch B, Mellinger U, Breitbarth H, Graser T. Influence of a continuous combined HRT (2 mg estradiol valerate and $2 \mathrm{mg}$ dienogest) on postmenopausal depression. Climacteric 2004;7:301-311.

130. Schmidt PJ, Ben Dor R, Martinez PE, et al. Effects of Estradiol Withdrawal on Mood in Women With Past Perimenopausal Depression: A Randomized Clinical Trial. JAMA Psychiatry 2015;72:714-726.

131. Gordon JL, Rubinow DR, Eisenlohr-Moul TA, Xia K, Schmidt PJ, Girdler SS. Efficacy of Transdermal Estradiol and Micronized Progesterone in the Prevention of Depressive Symptoms in the Menopause Transition: A Randomized Clinical Trial. JAMA Psychiatry 2018;75: 149-157.

132. Allen RH, Cwiak CA. Contraception for midlife women. Menopause 2016;23:111-113.

133. Yonkers KA, Brown C, Pearlstein TB, Foegh M, Sampson-Landers C, Rapkin A. Efficacy of a new lowdose oral contraceptive with drospirenone in premenstrual dysphoric disorder. Obstet Gynecol 2005; 106:492-501.

134. Pearlstein TB, Bachmann GA, Zacur HA, Yonkers KA. Treatment of premenstrual dysphoric disorder with a new drospirenone-containing oral contraceptive formulation. Contraception 2005;72:414-421.

135. Santoro N. Perimenopause: From Research to Practice. J Womens Health (Larchmt) 2016;25:332-339.

136. Santoro N, Teal S, Gavito C, Cano S, Chosich J, Sheeder J. Use of a levonorgestrel-containing intrauterine system with supplemental estrogen improves symptoms in perimenopausal women: a pilot study. Menopause 2015;22: 1301-1307.

137. Lynch D, Laws KR, McKenna PJ. Cognitive behavioural therapy for major psychiatric disorder: does it really work? A meta-analytical review of well-controlled trials. Psychol Med 2010;40:9-24.

138. Twomey C, O'Reilly G, Byrne M. Effectiveness of cognitive behavioural therapy for anxiety and depression in primary care: a metaanalysis. Fam Pract 2015;32:3-15.

139. Weitz ES, Hollon SD, Twisk J, et al. Baseline Depression Severity as Moderator of Depression Outcomes Between Cognitive Behavioral Therapy vs. Pharmacotherapy: An Individual Patient Data Meta-analysis. JAMA Psychiatry 2015;72:1102-1109.

140. Hollon SD, DeRubeis RJ, Fawcett J, et al. Effect of Cognitive Therapy With Antidepressant Medications vs. Antidepressants Alone on the Rate of Recovery in Major Depressive Disorder A Randomized Clinical Trial. JAMA Psychiatry 2014;71:1157-1164.

141. Hollon SD, DeRubeis RJ, Shelton RC, et al. Prevention of relapse following cognitive therapy vs. medications in moderate to severe depression. Arch Gen Psychiatry 2005; $62: 417-422$.
142. Khoshbooii R, Hassan SAB, Hamzah MSGB, Binti Baba M. Effectiveness of Group Cognitive Behavioral Therapy on Depression among Iranian Women around Menopause. Australian Journal of Basic and Applied Sciences 2011;5: 991-995.

143. Brandon AR, Minhajuddin A, Thase ME, Jarrett RB. Impact of reproductive status and age on response of depressed women to cognitive therapy. J Womens Health (Larchmt) 2013;22:58-66.

144. Cooney GM, Dwan K, Greig CA, et al. Exercise for depression. Cochrane Database Syst Rev 2013;CD004366.

145. Perez-Lopez FR, Martinez-Dominguez SJ, Lajusticia H, Chedraui P, Health Outcomes Systematic Analyses P. Effects of programmed exercise on depressive symptoms in midlife and older women: A metaanalysis of randomized controlled trials. Maturitas 2017;106:38-47.

146. Chim H, Tan BH, Ang CC, Chew EM, Chong YS, Saw SM. The prevalence of menopausal symptoms in a community in Singapore. Maturitas 2002;41:275-282.

147. Juang KD, Wang SJ, Lu SR, Lee SJ, Fuh JL. Hot flashes are associated with psychological symptoms of anxiety and depression in peri- and post- but not premenopausal women. Maturitas 2005;52:119-126.

148. Gallicchio L, Schilling C, Miller SR, Zacur H, Flaws JA. Correlates of depressive symptoms among women undergoing the menopausal transition. J Psychosom Res 2007;63:263-268.

149. Tangen T, Mykletun A. Depression and anxiety through the climacteric period: an epidemiological study (HUNTII). J Psychosom Obstet Gynaecol 2008;29:125-131.

150. Zainal NZ. Depressive symptoms in middle-aged women in peninsular Malaysia. Asia Pac J Public Health 2008;20: 360-369.

151. Yen JY, Yang MS, Wang MH, Lai CY, Fang MS. The associations between menopausal syndrome and depression during pre-, peri-, and postmenopausal period among Taiwanese female aborigines. Psychiatry Clin Neurosci 2009;63:678-684.

152. Avis NE, Brambilla D, McKinlay SM, Vass K. A longitudinal analysis of the association between menopause and depression. Results from the Massachusetts Women's Health Study. Ann Epidemiol 1994;4: 214-220.

153. Maartens LW, Knottnerus JA, Pop VJ. Menopausal transition and increased depressive symptomatology: a community based prospective study. Maturitas 2002;42:195-200.

154. Freeman EW, Sammel MD, Rinaudo PJ, Sheng L. Premenstrual syndrome as a predictor of menopausal symptoms. Obstet Gynecol 2004;103:960-966.

155. Kravitz HM, Schott LL, Joffe H, Cyranowski JM, Bromberger JT. Do anxiety symptoms predict major depressive disorder in midlife women? The Study of Women's Health Across the Nation (SWAN) Mental Health Study (MHS). Psychol Med 2014;44:2593-2602.

Address correspondence to: Pauline M. Maki, PhD Department of Psychiatry Neuropsychiatric Institute, MC913 912 S. Wood Street Chicago, IL 60612

E-mail: pmaki1@uic.edu 